\title{
Dimensions of Altruism:
}

\section{Do Evaluations of Prosocial Behavior Track Social Good or Personal Sacrifice?}

\author{
Samuel G. B. Johnson 1,2,3,4 \\ ${ }^{1}$ University of Waterloo, Department of Psychology \\ 2 University of Warwick, Department of Psychology \\ ${ }^{3}$ University of Bath School of Management, Division of Marketing, Business, \& Society \\ ${ }^{4}$ University College London, Centre for the Study of Decision-Making Uncertainty
}

Corresponding Author: Sam Johnson

Email for Correspondence: $\quad \underline{\text { samuel.johnson@,uwaterloo.ca }}$

Word Count: $\quad 14,125$ (main text)

Last Revised: $\quad 7$ September 2022 (submitted to journal)

Author note: I thank Richard Fairchild, Zarema Khon, Haiming Hang, Josh Knobe, Aaron Shine, and Yvetta Simonyan for useful discussion and Seo Young Park for help with the stimuli. Subsets of these studies were presented at the Association for Consumer Research (ACR), Cognitive Economics Society, and Cognitive Science Society meetings, as well as the Vice-Chancellor's Research Day at the University of Bath and seminars at London Business School, the New School, Princeton University, Purdue University, and the Universities of Kansas, Warwick, and Waterloo. I thank the audiences and conference reviewers for invaluable feedback. A non-archival conference paper reporting Studies 1 and 2 was published in the Proceedings of the Cognitive Science Society (Johnson, 2019). Funding for this research was provided by the University of Bath School of Management. Data are available at OSF (https://bit.ly/2Dj4QV4). 


\begin{abstract}
Do we praise prosocial acts because they produce social benefits or because they entail a personal sacrifice? Seven studies demonstrate that people primarily rely on personal cost rather than social benefit when evaluating prosocial actors. This occurs because sacrifice, but not benefit, is taken as a signal of moral character and an input to reputational judgments (Studies 1 and 2), reflecting a "character $=$ sacrifice" heuristic predicted by costly signaling theory. The studies test four possible boundary conditions, finding that the effects are similar for actions that benefit one's own country versus foreigners (Study 3), but differ for donations of time (Study 4), when information about personal sacrifice is unavailable (Study 5), and when high-cost but ineffective acts are pitted directly against low-cost but effective acts in joint evaluation (Study 6). Inferences about the signaling value of donations differed sharply from intuitions about warm glow, which strongly favored more effective donations (Study 7). These results help to account for the ineffectiveness of many charitable activities but also suggest directions for incentivizing effective charity.
\end{abstract}

Keywords: Moral judgment, prosocial behavior, charitable giving, costly signaling, reputation 


\section{Introduction}

People are surprisingly generous. Americans alone donated nearly half a trillion dollars to charity in 2021 (Giving USA, 2022). This is a mind-boggling number-what could society actually buy with a half trillion dollars? The estimated cost of eradicating malaria from the globe-which causes hundreds of thousands of deaths per year-would be about \$90-120 billion total (Gates Foundation, 2020); ending world hunger is estimated to cost between $\$ 7-265$ billion per year (Fan et al., 2018); and we could reduce $\mathrm{CO}_{2}$ emissions by two-thirds for an annual net cost of $\$ 230-400$ billion (McKinsey, 2009). Many of the world's most pressing problems could be seriously alleviated or even eliminated merely with the current levels of charitable activity, to say nothing of the prospects for increasing our generosity. Yet, the attentive reader will have noticed: that many people die of malaria every year, that many people globally are malnourished, that the Earth's temperature continues to climb. Why do these problems persist despite global giving more than sufficient to address them?

In this article, I explore one potential mechanism to account for this apparent paradox: Donations are motivated by the desire to signal our character to others, yet the effectiveness of our donations has little impact on the character inferences made by third-parties. Thus, even though altruistic acts can be motivated by reputational concerns, those reputational concerns themselves are unaffected by how effective our donations are. If so, reputational dynamics can explain simultaneously the ineffectiveness of most charity against a background of generosity.

For example, suppose Laura donates $\$ 100$ to the Malaria Consortium. We find this an admirable act, but why exactly? Because Laura sacrificed $\$ 100$ (her personal cost)? Or because this donation was used to prevent 4 children from contracting malaria provide anti-malaria drugs to 4 children for a year (the social benefit)? Indeed, all prosocial acts by definition entail a personal cost and realize a social benefit - and while these factors are typically correlated, this correlation is far from perfect as reflected in the wildly varying efficacies of different charities (Caviola et al., 2020). Which is the main driver of reputation?

From a philosophical perspective, it seems that the benefits should loom larger. The reason why we want more people to donate to the Malaria Consortium is because it prevents children from dying of malaria, not because it requires sacrifice. This is the fundamental insight of utilitarian moral philosophy (Bentham, 1789/1907; Mill, 1861/1998): We should act to maximize happiness and minimize pain. Benefits are morally good, costs are not. Members of the effective altruism movement (MacAskill, 2015; Singer, 2015) aim to follow the dictates of utilitarianism, achieving the greatest good for the greatest number. Although effective altruists often donate a large fraction of their income, they are perhaps best known for their careful research in order to maximize the effectiveness of each dollar. According to utilitarians and effective altruists, Laura's donation is praiseworthy because it benefited others.

Psychologically, however, the costs may loom larger. This follows from signaling theory, an idea developed in economics (Spence, 1973) and biology (Zahavi, 1975), and which has received increasing attention in moral psychology and consumer behavior (Bellezza, Gino, \& Keinan, 2014; Bhogal et al., 2020; Berger \& Ward, 2010; Griskevicius et al., 2007; Miller, 2009; Sperber \& Baumard, 2012; Sundie et al., 2011). From this perspective, morality is often motivated by reputation maintenance concerns, but our reputations are not equally served by all possible actions. Actions most diagnostic of underlying traits are those that are costly and most directly under our control. This suggests that demonstrating a willingness to sacrifice, rather than the social benefits that might ensue, is the key reason why prosocial actions are reputation-enhancing. Laura's donation deserves our praise because of her personal sacrifice.

To examine these questions, this article reports seven studies testing the reputational inferences made in response to prosocial actions, teasing apart the relative importance of the degree of personal 
sacrifice (small vs. large donations) versus degree of social benefit (few vs. many beneficiaries). These studies also test potential moderators, including character information (present vs. absent), beneficiary location (domestic vs. foreign), resource type (money vs. time), sacrifice information (present vs. absent), and evaluation mode (separate vs. joint), and examine whether similar mechanisms are at work in assessment of emotional gratification rather than social signaling.

This article makes three primary theoretical contributions to the literature on prosocial behaviorcharitable giving in particular. First_along with seminal articles by Zhang and Epley (2009), Kawamura, Ohtsubo, and Kusumi (2020), and Burum, Nowak, and Hoffman (2020) — this article is among the first to separate out the orthogonal impacts of the costs and benefits of prosocial behaviors. To my knowledge, it is unique in assessing the reputational implications of costs versus benefits of charitable giving for realistic donations. Second, the economics literature highlights the role of reputational considerations in motivating charitable giving (e.g., Glazer \& Konrad, 1996; Harbaugh, 1998), but has not unpacked the determinants of how donations signal reputation as the current article does. Third, this article's tests of boundary conditions contribute to conversations around the moderators of charitable giving, including the role of time versus money donations (e.g., Johnson \& Park, 2021; Liu \& Aaker, 2008; Reed, Aquino, \& Levy, 2007) and evaluation mode (Dhar \& Sherman, 1996; Hsee, 1996), bringing a signaling theory perspective to these conversations.

\section{Motives for Prosocial Behavior}

People behave prosocially for a variety of reasons. The reason most typically invoked by donors themselves is that they want to do good. Although the power of pure altruism has been questioned both in psychology (Batson, 1987) and in our lay theories (Critcher \& Dunning, 2011), purely altruistic motives do seem to exist. Batson and Shaw (1991) argue that empathy can motivate pure altruism, and people higher in the belief in pure altruism tend to behave more altruistically themselves (Carlson \& Zaki, 2020). Indeed, some people take this to the extreme. MacFarquhar (2016) relates the story of a couple who adopts two children, only to realize they were failing to help countless other children in need; they adopted a further 18 children, greatly reducing the standard of living for themselves and their biological children.

But people also have self-interested motives for prosocial behavior. One is the motive to feel good, known as "warm-glow" giving (Andreoni 1990). Many facts about the psychology of prosocial behavior seem best explained by such motives. Most directly, positive emotions lead to prosocial behavior and vice versa (Aknin, Van de Vondervoort, \& Hamlin 2018), suggesting a positive feedback loop: feeling a "warm glow" leads to prosocial actions, which in turn produce a "warmer glow." Unfortunately, some factors that make donations have a "warmer" glow are at odds with effective giving. People "diversify" their charitable donations across multiple charities even within the same category and even when some had higher social value (Null, 2011); favor causes with which they have a personal connection even if the prosocial benefits are smaller (Berman et al. 2018); avoid charities with high levels of overhead even if they are more cost-effective overall (Gneezy, Keenan, \& Gneezy, 2014); and prefer to help identifiable over anonymous or statistical victims (Small, Loewenstein, \& Slovic, 2007). Although there is not consensus on the causes of all of these biases, they are all plausibly linked to the motivation to maximize emotional gratification.

In this article, we focus on a second impure motivation for altruism-looking good: social signaling or reputation maintenance. Whereas warm glow giving can be thought of as signaling one's positive traits to oneself, reputation maintenance is about signaling those traits to others. Altruism is, in fact, associated with prestige, both in lab (Hardy \& Van Vugt, 2006; Willer, 2009) and field settings (Price, 2003; Smith \& Bird, 2000). As such, donors seem to act in ways aimed at maximizing their social reputation. For example, donations to organizations such as symphonies or universities are very rarely 
anonymous (Glazer \& Konrad, 1996) and donors usually give the minimum to be publicly listed in a given category (e.g., donating $\$ 1000$ to get into the $\$ 1000-\$ 2499$ category; Harbaugh, 1998). Donors are also attuned to how to how others will interpret their motives: They are less generous in public when they believe their donations will be seen as extrinsically rather than intrinsically motivated (Ariely, Bracha, \& Meier, 2009). Similarly, eco-friendly behaviors are partly status-seeking: People are likelier to buy green products when status motives are active, when in public, and when the products are more expensive (Griskevicius, Tybur, \& Van den Bergh, 2010). Thus, to understand the market for charitable contributions, we must understand the underlying reputational dynamics.

\section{Moral Reputation}

Doing good, feeling good, and looking good are all proximal motives for altruistic actions. However, since natural selection favors organisms that survive and reproduce-and altruistic acts do not straightforwardly promote these goals-evolutionary biologists have had to look deeper to understand the ultimate biological roots of altruism (Rand \& Nowak, 2013). Three main mechanisms have been identified. Kin selection (Hamilton, 1964) occurs when one takes a cost to benefit a genetic relative, since such actions tend to promote one's genes. Reciprocal altruism or direct reciprocity (Trivers, 1971) occurs when one helps another with the expectation of being helped in return. And finally, signaling or indirect reciprocity (Nowak \& Sigmund, 1998) occurs when one's altruism signals to third-parties that one is reputable, leading to more opportunities for mutually beneficial activities in the future. This signaling mechanism is the key to our theoretical framework.

Signaling refers to actions taken in an attempt to communicate difficult-to-observe characteristics to others (Spence, 1973). For example, conspicuous consumption signals wealth (Veblen, 1899/1994), wearing non-conforming clothing signals status and competence (the "red sneakers effect"; Bellezza et al., 2014), and genuine (Duchenne) smiles signal intrinsic motivation (Cheng, Mukhopadhyay, \& Williams, 2020). People can even use more sophisticated signaling strategies targeted at a particular audience, such as ironic use of brands (Warren \& Mohr, 2019) which can send desired signals both to one's in-group and out-group; and inconspicuous consumption of subtle brand logos (Berger \& Ward, 2010), which signals sophistication to others knowledgeable about fashion.

For a signal to be effective, it must be (i) more observable than the trait being signaled, (ii) correlated in the audience's mind with that trait, and (iii) difficult to fake. For example, in the "red sneakers effect" (Bellezza et al., 2014), social status is difficult to observe directly, but clothing choices are readily seen; the audience associates high-status people with non-conforming clothing; and the signal tends to be honest because low-status non-conformers pay a social cost. This is core to costly signaling theory (Gintis, Smith, \& Bowles, 2001; Zahavi, 1975): Signals are trustworthy to the extent that they are costly to the sender. For example, conspicuous consumption of wealth cannot be easily faked because only a genuinely wealthy person can afford it. One reason that people strongly dislike hypocrites is because a hypocrite has sent a false signal about their own conduct (Jordan et al., 2017); the stigma of hypocrisy may thus impose a social cost that disincentivizes such false signaling behaviors.

One's perceived propensity to be helpful and trustworthy-moral reputation-is critically important to modern social life (Goodwin, Piazza, \& Rozin, 2014) and almost certainly attained this psychological prominence due to its overpowering importance in our evolutionary environment as our ancestors determined who they could trust (Sperber \& Baumard, 2012; Wright, 1994). How might one signal one's moral reputation? As noted above, there is extensive evidence that prosocial behaviors such as charitable giving are motivated partly by reputation maintenance. The central question in this article is to what extent the costs versus the benefits of those contributions influence the reputational implications of prosocial behavior. 
A few lines of research provide indirect evidence consistent with the notion that costs loom larger than benefits in the reputational calculus. First, consistent with a signaling account, people are highly attuned to a donor's motives. Donors are viewed more favorably when they are seen as emotionally invested (Barasch et al., 2014; Johnson \& Park, 2020) or giving with communal intentions (Gershon \& Cryder, 2018), but less favorably when they benefit financially (Newman \& Cain, 2014), are personally affected by the cause (Lin-Healy \& Small, 2012), or are seen as motivated mainly by social signaling (Carlson \& Zaki, 2018), for instance because they are bragging (Berman et al., 2015). Together, this work suggests some relationship between sacrifice and social praise for prosocial acts. Second, Klein and Epley (2014) have examined the relationship between the magnitude of both selfish and selfless actions (e.g., in dictator games) and found that people are sensitive to these magnitudes only for selfish but not selfless ones. This study did not tease apart the roles of benefits and costs, but could be interpreted as implying that people would not be sensitive to the degree of sacrifice. Third, Olivola and Shafir (2013) find that people view painful and effortful experiences as more meaningful in charity contexts, motivating greater generosity. This further supports the association between sacrifice and merit-worthy charity.

A further three studies have directly manipulated the costs and benefits of generous acts, although only one included measures of moral reputation. Zhang and Epley (2009) compared the attention paid by givers versus receivers to the costs and benefits of favors, finding that givers attend more to costs (and expect to be reciprocated on that basis) whereas receivers attend more to benefits (and actually reciprocate on that basis). Kawamura et al. (2020) examined how interpersonal warmth and competence are assessed from prosocial costs and benefits (Kawamura et al., 2020), finding that benefits were associated with both warmth and competence, while costs were associated only with warmth. However, the within-subjects design used by Kawamura et al. (2020) is likely to have affected these conclusions (see Study 6).

Most directly relevant, Burum, Nowak, and Hoffman (2020) measured the social reward associated with more effective giving. In their most relevant study (Study 3), one group of participants were given the opportunity to donate their $\$ 0.30$ bonus to charity; some of these donors were told that any contributions would be matched by the experimenter if they chose to give (so that the charity would receive $\$ 0.60$ ), and for other donors there was no such match. A separate group of participants was given the option to reward each donor and rated their moral character. Donors were rewarded more, and their character rated more highly, when they donated rather than did not donate, but not when their donation was matched by the experimenter.

Although the null effect of effectiveness is broadly consistent with our predictions, two aspects of this study raise concerns about its generalizability. First, the manipulation of social benefit (experimenter match vs no match) was completely exogenous to the donor, so any individual donor did not have the opportunity to give to a more effective cause. Since judgments of causal and moral responsibility are sensitive to whether a choice was optimal or not (De Freitas \& Johnson, 2018; Johnson \& Rips, 2015), the fact that donors did not have a better option available may have led to equal attributions of responsibility. Second, the stakes were extremely small. A donation of $\$ 0.30$ may be seen as a token gesture rather than a genuine sacrifice, which makes comparisons to larger realworld donations challenging. (Of course, a strength of this research was that the use of small stakes permitted incentive-compatible designs.) Indeed, in this paradigm, participants were also insensitive to the amount given, which is distinct from our prediction that observers would be sensitive to the degree of sacrifice. This seems intuitively implausible for more realistic stakes. Are you really no more impressed by your friend who "rounds up" their supermarket purchase to the nearest dollar versus an effective altruist who donates $30 \%$ of their income? As we will see, this is likely to be an artifact of the extremely small stakes, which also raises the specter that insensitivity to effectiveness may likewise be an artifact. 
Although these lines of research are suggestive, none provides a direct and unambiguous answer to our question. Thus, we return to first principles and analyze costs and benefits from a signaling perspective.

First, the cost side. Signaling theory suggests that the extent to which one has made a large sacrifice or borne a large cost should be a strong signal of moral character. Because personal sacrifice is a cost, this cost should be seen as proportional to the altruistic intentions of the signaler, which are tightly linked with moral character judgments (Cushman, 2008). For example, we assume that Laura (from our earlier example) would not normally have been willing to sacrifice $\$ 100$ unless she had been motivated by her passion for the cause, which is why ulterior motives can crowd out the perception of prosociality (e.g., Berman et al., 2015; Lin-Healy \& Small, 2012; Newman \& Cain, 2014). There are two further reasons why sacrifice might be an especially strong signal. First, costs are typically under the direct control of the signaler and thus more diagnostic of intentions compared to noisier signals. Second, because costs are easily controllable, they can often be made easy to observe by third-parties. When Laura wrote her $\$ 100$ check to Oxfam, she has full control over both the amount of money and over the social context in which she writes the check or discusses her donation with others. Thus, we hypothesized a "character = sacrifice" heuristic:

H1: Prosocial acts higher in personal sacrifice will be associated with higher perceived moral character compared to acts lower in personal sacrifice.

Second, the benefit side. Unlike sacrifice, benefits may be only loosely associated with the donor's intention. Chance may intervene between the sacrificial act and the ensuing benefits, which could either attenuate or enhance the benefits. But "it's the thought that counts," and the thought is more directly measured by sacrifice. Once Laura writes her check, the actual effects of her donation can be influenced by a variety of factors outside Laura's control, most importantly what Oxfam decides to do with it. To the extent that people rely on benefits at all, according to costly signaling theory, it should be as a rough proxy for sacrifice. When the amount of sacrifice is known, benefits should be discounted. Moreover, it is probably more common for sacrifice rather than benefit information to be observable, at least in the context of charitable giving. Laura herself may not even know what was done with her money. Thus, we hypothesized:

H2: Prosocial acts higher in social benefits will not typically be associated with higher perceived moral character compared to acts lower in social benefits.

Although the ultimate motive of prosocial behavior is often maintenance of one's long-term reputation, the proximal motive for a particular action is more likely to be attaining social approval for that specific action. Adam Smith, for example, wrote in his Theory of Moral Sentiments (1759) of an "impartial spectator" we imagine in our minds who we consult to decide the propriety of an action. That is, one is less likely to explicitly ask "How will this action affect my reputation?" and instead more likely to ask "What would others say about this action?" even if these two questions often have similar answers.

Moral psychology has devoted great effort to analyzing how people evaluate individual actions. One view is that people often act on utilitarian intuitions (e.g., Greene et al., 2008), and to the extent this is true, social benefit rather than personal sacrifice should predominate in assessing the praiseworthiness of individual actions. However, character-based theories of moral judgment suggest that the function of praise and blame is precisely to motivate actions that serve one's long-term reputation (Uhlmann, Pizarro, \& Diermeier, 2015). Thus, moral evaluations often diverge from 
utilitarian norms. For example, people blame others for harmless actions accompanied by "wicked desires" (Inbar, Pizarro, \& Cushman, 2012) because such desires can signal poor moral character.

Put differently, this prior work suggests that people heuristically substitute the question "How praiseworthy is this action?" for the question "How does this action affect my judgment of this person's character?" (which itself can be informed by heuristics such as the "character = sacrifice" heuristic). This suggests that praise judgments should be tightly coupled with character judgments. If so, then making a cue less diagnostic of moral character should also reduce that cue's influence on praise. Specifically, providing background information that firmly establishes an individual's upstanding moral character should make people less attentive to the degree of sacrifice in evaluating the praiseworthiness of a prosocial action. That is:

H3a: The use of sacrifice and benefit information in evaluating moral character will be similar to their use in evaluating the moral praiseworthiness of individual acts.

H3b: When character information is provided, the sacrifice of a prosocial act will be less strongly associated with praise than when character information is not provided.

\section{Potential Boundary Conditions}

In addition to testing the basic predictions of this costly signaling framework, this article tests four potential boundary conditions on the "character = sacrifice" heuristic. The first two (beneficiary's social group and resource type) are differences in the donations themselves, linking to literature on prosocial behavior. These boundary conditions act on the appropriateness of the "character = sacrifice" heuristic. The second two (no sacrifice information and task transparency) concern the information available during the task, linking to literature on heuristics. These boundary conditions act on the need for the "character $=$ sacrifice" heuristic.

Beneficiary's social group. People are known to be parochial in their donations, favoring causes that benefit others in their social group, and in particular their own country (Baron \& Szymanska, 2011). This effect probably arises for several reasons (Nagel \& Waldmann, 2013). We think of out-groups more abstractly and as more homogeneous compared to our in-group (Park \& Rothbart, 1982), which may make beneficiaries less identifiable and reduce empathy (Small et al., 2007). Further, in-group members are, by definition, more likely to be in our social circle and other in-group members may be more attentive to their welfare compared to that of outsiders. Thus, while it may be sacrifice that impresses us when it comes to helping out-group members, we may attend to benefits when evaluating actions helping the in-group. This suggests:

H4: When the beneficiaries are domestic, the benefits of a prosocial act will be more associated with character and praise than when the beneficiaries are foreign.

Resource type. The discussion so far has been assuming that the resource sacrificed is money, which is the most common resource studied in prior work on prosocial behavior. But people often donate their time as well, and people are known to think differently about time and money, both in consumer behavior broadly (Mogilner \& Aaker, 2009; Okada \& Hoch, 2004; Saini \& Monga, 2008) and in the domain of prosocial behavior in particular (Johnson \& Park, 2020; Liu \& Aaker, 2008; Reed, Aquino, \& Levy, 2007). For example, donations of time are seen as more expressive of preferences than donations of money, which leads people high in moral self-identity to prefer donations of time rather 
than money (Reed et al., 2007) and third-parties to judge donors of time more favorably (Johnson \& Park, 2020). One possibility we investigate is that, while the effects of sacrifice and benefits on judgments of morality may be similar for money and time donations, they may differ for judgments of competence which also feed into praise. Specifically, the degree of sacrifice may be seen as diagnostic of competence for money donations (because it implies that one has enough resources to afford the sacrifice) but not for time donations (because it implies that one works inefficiently). If this auxiliary hypothesis proves true (as tested in the Web Appendix), the theoretical framework implies that:

H5: When donations are of time, the sacrifice of a prosocial act will be less strongly associated with praise than when the donation is of money.

No sacrifice information. The foregoing has assumed that social perceivers have access to information both about personal sacrifice and social benefit, and has assumed that sacrifice information would trump benefit information because it is seen as more diagnostic of character (the "character = sacrifice" heuristic). However, when sacrifice information is unavailable, people may use benefits to infer the degree of sacrifice. If all we know about Laura is that her donation helped a large (vs. small) number of people, we might assume that Laura must have made a relatively large (vs. small) sacrifice to accomplish this. The "character = sacrifice" heuristic would then imply that more beneficial actions should be seen as more diagnostic of character and more praiseworthy. That is:

H6: When the amount of personal sacrifice is unknown, the benefits of prosocial act will be used as a cue to sacrifice and therefore to praise.

Task transparency. People rely more on heuristics when tasks are relatively opaque and complex. For example, people are less prone to the conjunction fallacy and base rate fallacy when the information is more readily digestible (Barbey \& Sloman, 2007; Tversky \& Kahneman, 1983) and are more able to consider multiple possibilities at once in prediction tasks when all aspects of the task are quantified rather than left qualitative, increasing the transparency of the task (Johnson, Merchant, \& Keil, 2020). In all of these cases, people have explicit beliefs-in these cases, beliefs about how probabilities are calculated-which can be used when the relevant comparisons are made salient or additional contextualizing information is provided. Heuristics are used largely to solve these problems in the many realistic situations where all of this information is not readily available (Shah \& Oppenheimer, 2008).

Since our argument is that "character $=$ sacrifice" is an adaptive heuristic for evaluating moral reputation, one might expect people to hold more sophisticated explicit theories of morality, in the same way that people hold more sophisticated explicit theories of probability that deny that two things happening can be likelier than one thing happening. Plausibly, when the task is made highly transparent, people will be more willing to rely on benefit information if they explicitly believe that the purpose of prosocial behavior is helping others rather than sacrifice. We considered two ways of increasing task transparency. First, we contrasted separate evaluation, where all options are evaluated individually, with joint evaluation, where options are evaluated side-by-side. Joint evaluation increases task transparency and can sometimes lead to preference reversals when attributes differ in evaluability or how readily they are contextualized (Hsee, 1996). Given the higher transparency of joint evaluation, we hypothesized:

H7a: In joint evaluation mode, benefit information will be prioritized over sacrifice information when evaluating prosocial acts. 
A further way of increasing task transparency is to make the attributes more alignable or commensurable across options (Dhar \& Sherman, 1996; Gentner \& Markman, 1997; Walasek \& Brown, 2020). For example, it is easier to compare donations that provide malaria treatment to 10 vs. 100 children rather than comparing charities providing malaria treatment versus food. Thus:

H7b: Benefit information will be more strongly prioritized in joint evaluation mode when the benefits are more (vs. less) readily aligned.

Signaling vs warm glow. I distinguished earlier between social signaling ("looking good") and warm glow ("feeling good") as motives for prosocial actions. Both likely play a role in real-world prosocial behavior; indeed, in at least some situations, public recognition for a donation can reduce giving because it undermines the donors' beliefs that their donations were genuinely altruistic (Savary \& Goldsmith, 2020).

The preceding arguments for why personal sacrifice is a stronger signal than social benefit are specific to the context of signaling to others who face greater uncertainty about our actions or motives. There are good arguments either way as to whether warm glow would be more sensitive to sacrifice or to benefits. Given plausible arguments on both sides, I do not formally hypothesize an effect one way or the other but treat this as a research question.

On the one hand, the empathy-altruism hypothesis (Batson et al., 1991) says that empathic emotions toward the recipients of our altruistic actions motivate those actions. Plausibly, there would be some relationship between the amount of good we do and the strength of those feelings. That said, there is evidence that emotional reactions are generally quite insensitive to scope (Hsee \& Rottenstreich, 2004; Slovic, 1997; Small et al., 2007), so any sensitivity to social benefit might be modest.

On the other hand, our emotions sometimes seem to act as a proximal mechanism to carry out the schemes of natural selection. For example, anger can cause us to take risks that are irrational in the moment, such as fighting a much bigger bully. Yet because would-be bullies know that others are prone to such irrational risk-taking, they often refrain from bullying in the first place (Frank, 1988). If this analysis is correct, then seemingly irrational emotions are actually the proximal means of maximizing game-theoretic utility without consciously doing so. Analogously, perhaps our emotions are a proximal means of social signaling without consciously doing so. In this case, the donations that maximize warm glow should also be those that maximize signaling value.

\section{Overview of Studies}

These hypotheses are tested across seven studies, plus four replication studies and a further study reported in the Web Appendix. Studies 1 and 2 test the core hypotheses (H1-H3) which identify the effects of a prosocial act's benefits and costs when manipulated orthogonally. Studies 3-6 test, respectively, $\mathrm{H} 4-\mathrm{H} 7$ and establish the boundaries of the key effects, while Study S1 in the Supplementary Materials tests an auxiliary hypothesis needed to make predictions in Study 4. Finally, Study 7 tests whether the effects of benefits and costs are similar for warm glow as for signaling.

To improve statistical robustness, we conducted additional, near-identical replication studies of Studies 1-4 which we also briefly report in the main text and include in internal meta-analyses to increase statistical power. Since Studies 1-4 rely on similar designs, the Supplementary Materials also include an internal meta-analysis with over 2000 participants that tests the core hypotheses with maximal power and quantifies the strength of the evidence for moderation.

\section{Study 1: Sacrifice versus Benefits}


Study 1 examined whether, absent further information about a person, judgments of that person's prosocial behavior depend primarily on the degree of personal sacrifice rather than social good (H1-2)

\section{Methods}

Participants in all experiments were recruited and compensated through Mechanical Turk and prevented from participating in multiple studies in this article. All sample sizes were set a priori. The target sample size of Studies $1-4(N=300)$ is sufficient to achieve $90 \%$ power for an effect size of $d$ $=0.38$. We also use internal replications and meta-analytic techniques throughout to further improve the precision of our estimates.

298 American participants $\left(56 \%\right.$ female, $\left.M_{\text {age }}=36.1\right)$ were recruited for Study 1. Participants were excluded from analysis if they failed an attention check (see below; $N=41$ ).

Participants read about a charitable donation benefiting people in a developing country. The charities focused on blindness, hunger, education, or disaster relief. The donations involved a lower or higher monetary contribution (to manipulate personal sacrifice), and were lower or higher in benefit (to manipulate social good), with both manipulations between-subjects. These conditions always differed from one another by one order of magnitude (a factor of 10), facilitating comparison of the effects of personal sacrifice and social benefit. For two of the vignettes, the beneficiary was an individual in the lower-benefit condition and a small group in the higher-benefit condition. For example:

Julia decided to make a donation to charity. She donated [\$200/\$2000] to a charity focused on international health. Her donation was used to cure [a child's/10 children's] blindness in Ethiopia.

For the other two vignettes, the beneficiary was a small group in the lower-benefit condition and a large group of people in the higher-benefit condition. For example:

Rob decided to make a donation to charity. He donated [ $\$ 125 / \$ 1250]$ to a charity focused on disaster relief. His donation was used to provide basic shelter to [10/100] people for one month after a hurricane in Guatemala.

On the same screen, participants rated the praiseworthiness of the action ("Please rate the moral praiseworthiness of Julia's action") on a scale from 0 ("Not very praiseworthy") to 10 ("Extremely praiseworthy"), and the actor's moral character ("Please rate Julia's moral character") on a scale from 0 (“Ordinary moral character") to 10 ("Saint-like moral character").

After the main task, participants checked whether each of the four donation targets was mentioned during the study, and participants making any incorrect responses were excluded.

Open science. Data for all studies are available at the Open Science Framework: https://bit.ly/2Dj4QV4. The studies were not preregistered.

\section{Results}

Participants used the degree of personal sacrifice, but not of social good, to inform judgments of moral praise and character. Whereas character judgments were significantly more positive when sacrifice was higher versus lower $[M=8.34, S D=1.72$ vs. $M=7.81, S D=1.86 ; F(1,253)=5.59, p=$ .019], they did not differ when benefit was higher versus lower $[M=8.11, S D=1.57$ vs. $M=7.95$, $S D=2.07 ; F(1,253)=0.32, p=.57]$. Similarly, praise judgments responded significantly to sacrifice $[M=8.98, S D=1.31$ vs. $M=8.47, S D=1.55 ; F(1,253)=7.27, p=.007]$ but not benefit $[M=8.66$, $S D=1.66$ vs. $M=8.70, S D=1.66 ; F(1,253)=0.09, p=.77]$. There was no interaction between these two factors for either character $[F(1,253)=0.42, p=.52]$ or praise judgments $[F(1,253)=0.21, p=$ $.65]$. 
Replication study. To further bolster support for this effect and to improve statistical power, a nearexact replication of Study 1 was conducted ( $N=300,24$ excluded using the same criteria as above). The only procedural difference was that the dollar amounts from Study 1 were divided by 10 to test whether these effects generalize to dollar amounts more typical of the average person's donations. Thus, the larger sacrifice condition from the replication study was the same as the small sacrifice condition from Study 1 (e.g., $\$ 200$ or $\$ 125$ in the example given above), while the smaller sacrifice condition was 10 times smaller ( $\$ 20$ or $\$ 12.50$, respectively).

The results of the original and replication studies (total $N=533$ ) were meta-analyzed using a multilevel model fit with the lme4 package for R (Bates, Mächler, Bolker, \& Walker 2014). An internal meta-analytic approach was used to maximize statistical power, following the recommendation of McShane and Böckenholt (2017). In the Supplementary Materials, we report a more detailed internal meta-analysis including all data from Studies 1-4 and their replications.

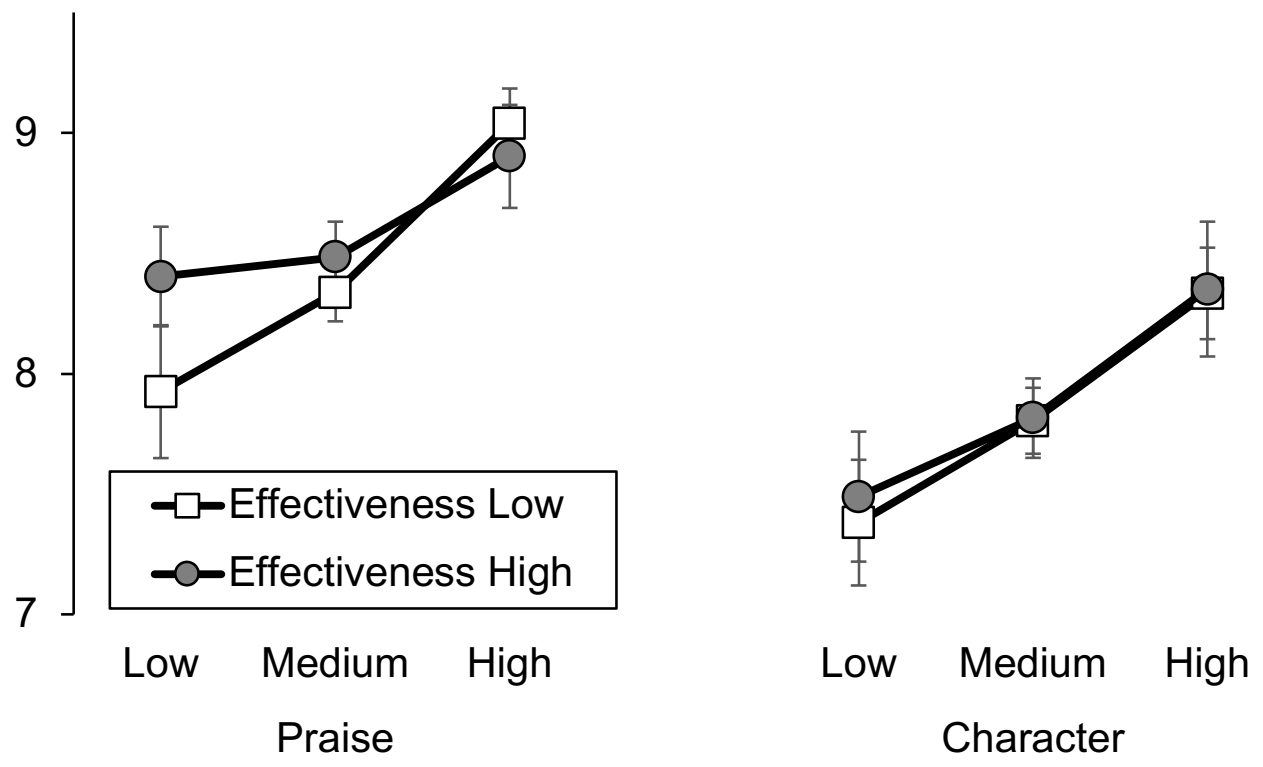

Contribution

Figure 1: Results of Study 1. The combined data of the original and replication studies are plotted, where the smaller and larger amounts in the original study map onto "medium" and "bigh" in the plot, and the smaller and larger amounts in the replication study map onto "low" and "medium" in the plot. (The lower condition from the original study is identical to the bigher condition from the replication study.)

The model included includes random intercepts for vignette and for study (original or replication) and fixed effects for personal sacrifice $(-1=$ low, $0=$ medium, $1=$ high $)$ and benefit $(-1 / 2=$ low, $+1 / 2=$ high $)$. This coding scheme for the fixed effects was used so that coefficients are comparable, reflecting the effect on the dependent variable of increasing an independent variable's value by one order of magnitude (e.g., from donating $\$ 20$ to $\$ 200$, donating $\$ 200$ to $\$ 2000$, or helping 10 to 100 people). Since the smaller amounts used in the original study are identical to the larger amounts used in the replication study, both map onto "medium" in this analysis, whereas the larger amount used in the original study maps to "high" and the smaller amount used in the original study maps to "low."

The data from both the original and replication studies are plotted in Figure 1. For character, there was a significant effect of sacrifice $[b=0.45, S E=0.12, p<.001$ using Satterthwaite's method to 
compute $p$-values $]$ but not benefit $[b=0.04, S E=0.16, p=.82]$. Likewise, for praise, there was a significant effect of sacrifice $[b=0.40, S E=0.11, p<.001]$ but not benefit $[b=0.17, S E=0.14, p=$ .23]. Adding interaction terms did not improve model fits $\left[\chi^{2} s<2.2, p s>.14\right]$.

\section{Discussion}

We see consistent evidence across two samples that people find more highly sacrificial behaviors more praiseworthy and diagnostic of character, holding constant their benefit, while they do not find more effective prosocial behaviors to be more praiseworthy or diagnostic of character, holding constant the amount of sacrifice. For praise, the meta-analytic coefficient on sacrifice was more than twice as large as the (non-significant) coefficient on benefit, while the disparity was even more extreme for character judgments. Moreover, these results do not seem to be due to low statistical power, as this meta-analytic test includes over 500 participants. These results support H1 and H2.

According to $\mathrm{H} 3$, the greater effect of sacrifice on praiseworthiness is mainly a downstream consequence of highly sacrificial actions being diagnostic of moral character. However, because character and praise were so tightly linked in Study 1, the causal order of these variables is difficult to tease apart. This is the main goal of Study 2.

\section{Study 2: The Role of Character Inference}

Character-based accounts of morality suggest that an action's moral praiseworthiness is a function of how diagnostic that action is for that person's moral character (H3a). Thus, giving an independent reputational cue that establishes a person's strong moral character should attenuate the effect of sacrifice on praise (H3b). Study 2 tests these hypotheses.

\section{Methods}

298 American participants (51\% female, $M_{\text {age }}=36.0$ ) were recruited for Study 2. Participants were excluded if they failed the same attention check used in Study $1(N=56)$.

Study 2 was identical to Study 1, except that the vignettes were altered to include information establishing the actor's altruistic moral character. For example:

\footnotetext{
Rob works as a receptionist, earning about $\$ 31,000$ per year. He donates about $30 \%$ of his salary each year to a variety of charitable causes.

One of the donations Rob decided to make this year was [ $\$ 125 / \$ 1250]$ to a charity focused on disaster relief. His donation was used to provide basic shelter to [10/100] people for one month after a hurricane in Guatemala.
}

The moral judgment question was rephrased so it was clear that it referred to this specific donation, rather than the pattern of charitable donations (e.g., "Please rate the moral praiseworthiness of Rob's [\$125/\$1250] donation”). Rephrasing this question to emphasize the magnitude of the contribution should, if anything, increase the salience of this factor. Similarly, highlighting the character's salary (to provide a reference point for the impressiveness of the character's charitable contributions) should increase the evaluability of the donations and therefore increase reliance on sacrifice. Thus, these factors work against the study's hypothesis.

\section{Results}

The effects of sacrifice (contribution amount) on perceptions of moral judgment and character were less pronounced in Study 2, when the donor's strong moral character was established, compared to Study 1, where it was not. This supports H3. 
Looking first at character judgments, we see that the character information provided in Study 2 successfully attenuated the diagnosticity of the donation for character. The effect of sacrifice on character was only marginally significant $[M=8.60, S D=1.19$ vs. $M=8.23, S D=1.93 ; F(1,238)=$ $3.50, p=.063]$, while the effect of benefit remained non-significant as in Study $1[M=8.52, S D=$ 1.53 vs. $M=8.24, S D=1.78 ; F(1,238)=1.70, p=.19]$, nor was there a significant interaction $[F(1,238)$ $=0.55, p=.46]$.

Given that the contribution amount is no longer diagnostic of character, we should see a weaker effect of contribution amount on praise. This is indeed what was observed. Neither sacrifice $[M=$ $8.80, S D=1.65$ vs. $M=9.02, S D=1.46 ; F(1,238)=1.72, p=.19]$ nor benefit $[M=8.76, S D=1.88$ vs. $M=9.01, S D=1.26 ; F(1,238)=1.25, p=.27]$ had a significant effect on praise, nor was the interaction significant $[F(1,238)=2.55, p=.12]$. Unlike Study 1, where the effect of sacrifice was much larger than the (non-significant) effect of benefit, here the two effects are roughly the same size (and both non-significant).

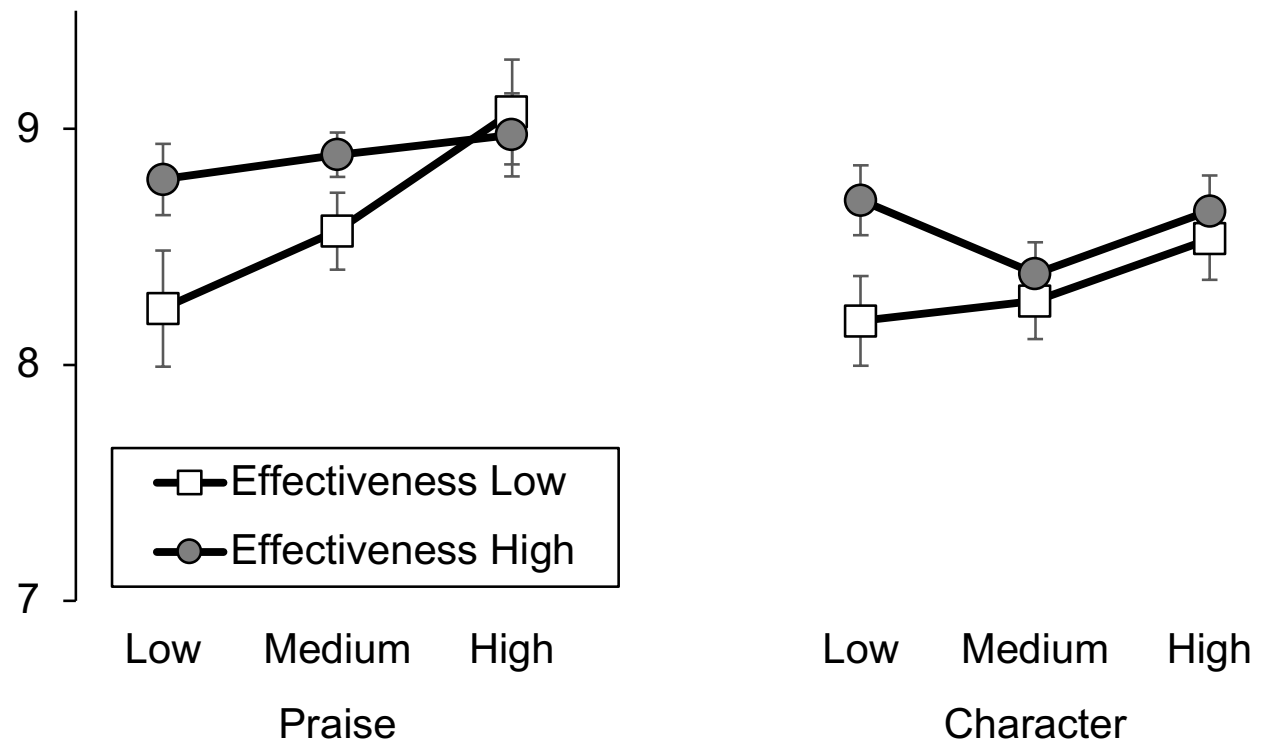

\section{Contribution}

Figure 2: Results of Study 2. The combined data of the original and replication studies are plotted, where the smaller and larger amounts in the original study map onto "medium" and "bigh" in the plot, and the smaller and larger amounts in the replication study map onto "low" and "medium" in the plot.

Replication study. As for Study 1, a near-exact replication of Study 2 was conducted $(N=302,35$ excluded), dividing all donation amounts by 10. To meta-analyze these studies, a multilevel model (total $N=509$ ) was fit with fixed effects of sacrifice and benefit conditions (same coding scheme as for Study 1) and random intercepts for vignette and study.

The data from both the original and replication studies are plotted in Figure 2. Looking first at character judgments, there was no significant effect of either sacrifice $[b=0.08, S E=0.10, p=.52]$ or benefit $[b=0.22, S E .=0.13, p=.11]$. Thus, the character information introduced in Study 2 has successfully made sacrifice nondiagnostic of character. Correspondingly, when we look at praise, the effect of sacrifice is smaller than it was in Study $1[b=0.24, S E=0.10, p=.013$; compared with $b=$ 0.40 for Study 1], whereas the effect of benefit is actually larger and now significant $[b=0.29, S E=$ $0.13, p=.031$; compared with $b=0.17$ for Study 1]. This effect of benefit was not predicted, and 
speculation about this result is given in the Discussion. Adding interaction terms did not improve model fit $\left[\chi^{2} s<2.7, p s>.10\right]$.

Moderated mediation. These data together can be used to test a process model accounting for how character information lowers the use of personal sacrifice to evaluate praiseworthiness. The signaling theory predicts moderated mediation - that is, the effect of sacrifice on praise would be mediated by character judgments $(\mathrm{H} 3 \mathrm{a})$, but this would only occur when character information is unavailable and sacrifice is deemed diagnostic of character (H3b).

This model was fit using the 'mediation' package for R (Tingley et al., 2014), fitting a model equivalent to Hayes' Model 8 with 10,000 bootstrap samples. When character information was missing (Study 1), there was a significant indirect pathway [ $b=0.23,95 \% \mathrm{CI}: 0.11$ to 0.37 ] and marginally significant direct pathway [ $b=0.17,95 \% \mathrm{CI}:-0.01$ to 0.35$]$, whereas when character information is given (Study 2), there was no significant indirect pathway [ $b=0.03,95 \% \mathrm{CI}$ : -0.05 to 0.12$]$ but a significant direct pathway $[b=0.21,95 \% \mathrm{CI}: 0.04$ to 0.38$]$. The difference in indirect effects led to a significant index of moderated mediation on the indirect [ $b=0.20,95 \% \mathrm{CI}: 0.04$ to 0.35$]$ but not the direct effect $[b=-0.05,95 \%$ CI: -0.29 to 0.20$]$. The analogous mediation and moderation effects for benefit were not significant.

\section{Discussion}

Together, Studies 1 and 2 tell a clear story about moral evaluations of prosocial acts. Without evidence of reputation, prosocial behaviors are evaluated mainly by their personal sacrifice (H1), rather than the social benefit (H2). This occurs because personal sacrifice is a controllable and visible signal of cooperativeness and thus a useful input to reputational judgments (H3a). Thus, when reputation is known, personal sacrifice is less relevant to moral evaluations (H3b).

One unexpected result was the emergence of a small effect of benefit in the Study 2 internal metaanalysis, when character information is provided. One possibility is that information about personal sacrifice attracts more attention than information about benefit, with the former, when deemed relevant, "crowds out" attention to the latter. Conversely, when prior character information is available and the observer's focus is not on establishing character, there is more room for both factors to influence praise judgments. However, as this effect was not hypothesized a priori it should be replicated before it is used to build further theory.

\section{Study 3: Domestic Beneficiaries}

Studies 3 and 4 turn to potential boundary conditions related to the nature of the prosocial action. Study 3 tests whether we would replicate the results of Study 1 when the beneficiaries are domestic rather than foreign. People tend to be parochial, prioritizing donations that benefit their own country, even if there are more effective causes abroad (Baron \& Szymanska, 2011). Therefore, even if people do not attend to social good in developing countries, they may attend to social good in their own country (H4). Study 3 tested this idea by asking about donations to charities benefiting Americans.

\section{Methods}

299 American participants $\left(61 \%\right.$ female, $\left.M_{\text {age }}=38.7\right)$ were recruited for Study 3. Participants were excluded if they failed the same attention check used in prior studies $(N=18)$.

Study 3 was identical to Study 1, except that the donations benefitted recipients in the United States. For example: 
Rob decided to make a donation to charity. He donated $[\$ 125 / \$ 1250]$ to a charity focused on disaster relief in the United States. His donation was used to provide basic shelter to [10/100] people for one month after a hurricane in South Carolina.

The dependent measures were the same as in Study 1.

\section{Results}

For character judgments, once again there was only a significant effect of sacrifice $[M=8.30, S D$ $=1.50$ vs. $M=7.94, S D=1.74 ; F(1,277)=4.24, p=.040]$, but not of benefit $[M=8.28, S D=1.70$ vs. $M=8.02, S D=1.56 ; F(1,277)=1,277)=1.39, p=.24]$, nor a significant interaction $[F(1,277)=$ $2.39, p=.12]$. These results are similar to Study 1, albeit somewhat less statistically robust. For praise, neither sacrifice $[M=8.86, S D=1.38$ vs. $M=8.61, S D=1.28 ; F(1,277)=2.57, p=.11]$ nor benefit $[M=8.28, S D=1.70$ vs. $M=8.02, S D=1.56 ; F(1,277)=2.62, p=.11]$ nor their interaction $[F(1,277)$ $=0.61, p=.43]$ reached significance.

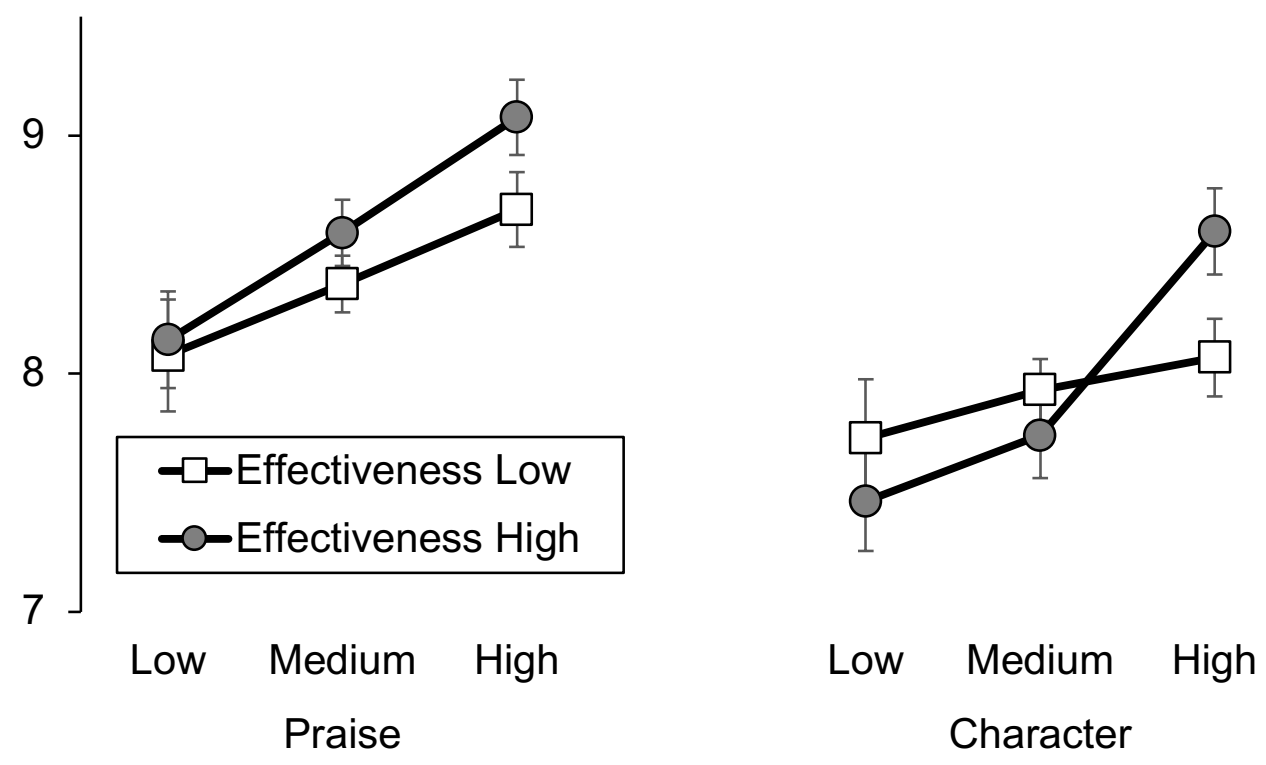

\section{Contribution}

Figure 3: Results of Study 3. The combined data of the original and replication studies are plotted, where the smaller and larger amounts in the original study map onto "medium" and "bigh" in the plot, and the smaller and larger amounts in the replication study map onto "low" and "medium" in the plot.

Replication study. Given that the effects on praise were in the predicted direction and (arguably) trending toward significance, it is important to consider replication to improve statistical power. As for Studies 1 and 2, we conducted an exact replication of Study 3 ( $N=300,18$ excluded), identical except that the donation amounts were divided by 10 .

The data from both the original and replication studies are plotted in Figure 3. Meta-analyzing the data using the same model as for the other studies (total $N=563$ ), there is a significant effect of sacrifice $[b=0.37, S E=0.10, p<.001]$ but not benefit $[b=-0.01, S E=0.15, p=.93]$ on character. Adding an interaction term does marginally improve model $\left[\chi^{2}(1)=3.23, p=.072\right]$ because the effect of sacrifice was driven by the high benefit condition. For praise, there were significant effects both of sacrifice $[b=0.37, S E=0.11, p=.013]$ and of benefit $[b=0.25, S E=0.13, p=.049]$, although this last effect is not very statistically robust. Adding an interaction term does not improve model fit $\left[\chi^{2}(1)\right.$ $=0.29, p=.59$ ]. 


\section{Discussion}

On the one hand, these results confirm the general finding of Study 1: Sacrifice has a consistently larger effect than benefit. This lends further support to H1 and H2. In some analyses, consistent with Study 1, benefit had no significant effect at all. But on the other hand, there were some hints that benefit might play some role. For character judgments, there was weak evidence that sacrifice plays a larger role when the benefit is high. A possible interpretation of this result is that people view ineffective donations as virtue signaling rather than genuine altruistic intent when they are ineffective, but only if they really care about the donation targets. A second piece of evidence is that in the metaanalysis of Study 3 and its replication, there was a (just barely) significant effect of benefit on praise judgments. An intriguing possibility is that praise judgments have both utilitarian and reputational inputs, and both pathways are in action when the donations benefit a cause seen as more important.

Since these results are not very statistically reliable, however, we cannot draw the strong conclusion that parochialism is a boundary condition on the use of benefit information, and thus the support for $\mathrm{H} 4$ is weak. The modesty of the evidence for $\mathrm{H} 4$ is also confirmed in the internal meta-analysis reported in the Supplementary Materials, which quantifies the evidence for moderation.

One possibility, noted by Burum et al. (2020), is that the mechanisms for altruism are quite distinct when the beneficiaries are related to the donor. Whereas reputation signaling (Nowak \& Sigmund, 1998) may be the main mechanism for giving to unrelated and unfamiliar strangers, kin selection (Hamilton, 1964) is likely to be more important for giving to relatives. Consistent with this possibility, Burum et al. (2020, Study 2) found that people were not only willing to give more of their income to save family members rather than strangers, but that their willingness to donate was related to the number of individuals when they were family rather than strangers. (Fortunately, this study was hypothetical.) We suspect we would find the same in our paradigm. Another interesting direction for future research would be to test this effect with a tighter in-group (e.g., shared acquaintances of both the donor and observer). In such a group, kin selection would not apply, but third-party observers may see the stakes of effective giving as higher and plausibly reputational consequences may be greater.

\section{Study 4: Time Donations}

A second possible boundary condition is which resource is contributed-time or money. People think differently about these resources in a number of ways (Liu \& Aaker, 2008; Mogilner \& Aaker, 2009; Okada \& Hoch, 2004; Reed et al., 2007), but for our purposes the key question is whether they differ in their signaling effects. Based on costly signaling theory, sacrifice rather than benefits should drive the moral signaling power of contributions of any scarce resource, including time. This would also be consistent with findings that people have a lay theory associating the way one spends one time (rather than money) with the self (Johnson \& Park, 2020; Reed et al., 2007), which leads time donations to be more tightly tied to moral character. Study S1 of the Supplementary Materials found that, indeed, sacrifice but not benefit is significantly tied to inferences about moral character.

However, time and money donations could differ along a further dimension-competence signaling. Large donations of money can signal competence because they are a sign of high income or wealth. But holding benefits constant, large donations of time might conversely signal inefficiency. For example, if one volunteers to assist in home building and manages only to roof a small fraction of a house, the longer one volunteered the less competent one would be at roofing. Study S1 found that, as expected, sacrifice was linked to competence for money but not time donations. Benefits were, in contrast, linked to competence for both resources.

Putting these ideas together, we can generate predictions. Moral signaling is similar for time and money donations, but sacrifice signals competence only for money donations. Therefore, we would 
expect sacrifice to less strongly associated with praise for time donations than we have seen for money donations in prior studies (H5).

\section{Methods}

299 American participants $\left(56 \%\right.$ female, $\left.M_{\text {age }}=38.3\right)$ were recruited for Study 4. Participants were excluded if they failed the same attention check used in prior studies $(N=25)$.

Study 4 was similar to Study 1, except that the donations were of time rather than money. This required different vignettes, since charities typically use labor and money for different purposes (e.g., buying materials for shelter vs. rescuing victims), so vignettes were adapted from Johnson and Park (2020). For example:

Rob decided to volunteer with a charity. He spent [2 hours /3 days / 30 days] working with a charity that transports people to flood zones. During his time volunteering, Rob's primary contribution was to rescue [2 / 20] flood victims in India.

The dependent measures were the same as in Studies 1-3.

\section{Results}

The results differed strikingly from those of Studies 1 and 3. Whereas in those studies of monetary donations, praise judgments tracked personal sacrifice but not social good, evaluations of time donations tracked social good at least as much as personal sacrifice. As in Study 2, this appears to be due to the differing role of character inferences.

For character judgments, neither sacrifice $[M=8.32, S D=1.32$ vs. $M=8.15, S D=1.66 ; F(1,270)$ $=1.02, p .=.31]$ nor benefit $[M=8.35, S D=1.41$ vs. $M=8.13, S D=1.56 ; F(1,270)=1.67, p=.20]$ nor their interaction $[F(1,270)=0.15, p=.70]$ was significant. However, for praise, both factors reached marginal significance-sacrifice $[M=8.67, S D=1.39$ vs. $M=8.36, S D=1.55 ; F(1,270)=$ $3.49, p=.063]$ and benefit $[M=8.66, S D=1.33$ vs. $M=8.39, S D=1.59 ; F(1,270)=2.98, p=.085]-$ but not their interaction $[F(1,270)=0.33, p=.56]$. This is a similar pattern to what we saw in Study 2 , where character information was not allowed to play its natural role.

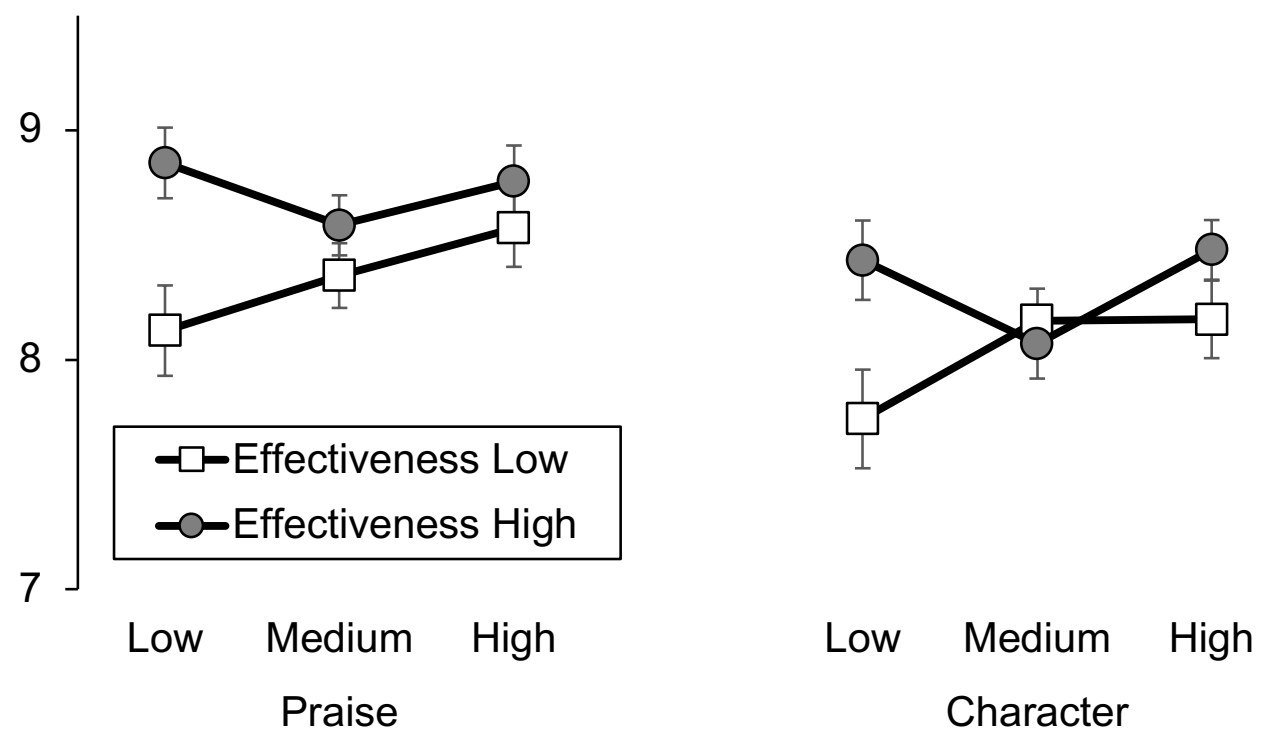

\section{Contribution}


Figure 5. Results of Study 4. The combined data of the original and replication studies are plotted, where the smaller and larger amounts in the original study map onto "low" and "medium" in the plot, and the smaller and larger amounts in the replication study map onto "medium" and "bigh" in the plot.

Replication study. As for Studies 1-3, we conducted a near-exact replication ( $N=299,22$ excluded), except in this case the time donations were made 10 times higher rather than lower (otherwise, donors would be volunteering for implausible lengths of time such as 12 minutes).

The data from both the original and replication studies are plotted in Figure 4. Meta-analyzing the data together using the same model as for the other studies (total $N=551$ ) leads to broadly similar results. There is no evidence for an effect of either sacrifice $[b=0.12, S E=0.09, p=.18]$ or benefit $[b=0.21, S E=0.13, p=.11]$ on character judgments; adding an interaction term does not improve fit $\left[\chi^{2}(1)=1.31, p=.25\right]$. For praise judgments, however, only the effect of benefit reaches significance $[b=0.36, S E=0.12, p=.004]$, whereas the effect of sacrifice is not significant $[b=0.18, S E=0.11$, $p=.14]$. Since adding an interaction term marginally improves model fit $\left[\chi^{2}(1)=3.02, p=.082\right]$, this suggests that the effect of benefit is mainly driven by judgments about those who sacrificed the least time.

Moderated mediation. Given the striking differences between the Study 1 and Study 4 results, we can test whether, as for Study 2, these results are the result of different character inferences being drawn based on the amount of sacrifice. Specifically, the theory-bolstered by the data from the Study S1 in the Supplementary Materials — predicts that character inferences should differ between Studies 1 and 4 , since larger sacrifices of money, but not time, are associated with greater competence, whereas they are equally associated with morality.

As for Study 2, we fit the equivalent of Hayes' Model 8 with 10,000 bootstrap samples. For monetary donations, there was a significant indirect effect of sacrifice on praise via character $[b=0.25$, 95\% CI: 0.12 to 0.40$]$ and a marginally significant direct effect $[b=0.15,95 \% \mathrm{CI}:-0.03$ to 0.33 ]. However, for time donations, neither the indirect $[b=0.06,95 \% \mathrm{CI}:-0.04$ to 0.16$]$ nor direct effects $[b=0.02,95 \% \mathrm{CI}:-0.11$ to 0.14$]$ were significant. This led to significant moderation on the indirect $[b=0.19,95 \% \mathrm{CI}: 0.02$ to 0.37$]$ but not the direct $[b=0.13,95 \% \mathrm{CI}:-0.09$ to 0.34$]$ pathway. This supports the conclusion that the amount of time donated is seen as less diagnostic of character than the amount of money donated, leading to a smaller effect on praise. The analogous indirect effects for benefit did not reach significance, consistent with the finding from Study S1 that benefit equally signals competence for money and time donations.

\section{Discussion}

These results support the theoretical framework. Specifically, since high sacrifice in money donations but not time donations signals competence, sacrifice should have a smaller effect here for time donations than it did in Study 1 for money donations. This is exactly what we see. Interestingly, there is some evidence for an effect of benefit in Study 4, which may reflect the signaling power of benefit for competence, as shown in Study S1.

\section{Study 5: Sacrifice Unknown}

Studies 5 and 6 test two boundary conditions related to the informational environment in which evaluations are made. The "character = sacrifice" heuristic suggests that when both sacrifice and benefit are known, character judgments and therefore praise track sacrifice rather than benefits. However, this pattern may not hold up when the amount of sacrifice is unknown. Under such 
conditions, people might use benefit as a means to infer sacrifice, in which case more effective donations should also be seen as more praiseworthy (H6). Study 5 tests this idea.

\section{Method}

600 American participants (58\% female, $\left.M_{\text {age }}=37.7\right)$ were recruited for Study 6. Participants were excluded if they failed the same attention check used in prior studies $(N=13)$. This sample size was chosen to equate statistical power with the combined analysis of the original and replication studies reported above under Studies 1-4.

Study 5 was similar to Study 1, except that information about personal sacrifice was not included. For example:

Rob decided to make a donation to a charity focused on disaster relief. His donation was used to provide basic shelter to $[10 / 100]$ people for one month after a hurricane in Guatemala.

The praise and character measures were the same as in Studies 1-4. In addition, Study 5 included measures of benefit ("Compared to other donations, do you think that Rob's donation was relatively effective or ineffective in helping people?") and sacrifice ("Compared to other donations, do you think that Rob's donation required him to make a relatively high or low personal sacrifice?") on scales from 0 ("Much less [effective / sacrifice] than average") to 10 ("Much more [effective / sacrifice] than average"). The praise/character questions were blocked and completed on the same page, as were the benefit/sacrifice questions. The order of the blocks was counterbalanced, as was the order of the benefit/sacrifice questions within their block.

\section{Results}

Unlike Studies 1-3, where sacrifice information was available, participants in Study 5 viewed more beneficial actions as more diagnostic of character and more praiseworthy.

The data were analyzed using a series of multilevel models, including a fixed effect for benefit ($1 / 2=$ low, $+1 / 2=$ high) and a random intercept for vignette, as for the internal meta-analyses of Studies $1-4$. There were no significant interactions with question order on any variable, so the analysis collapses across these variables.

Fitting this model separately for each dependent variable, there were effects of benefit condition on both perceived benefit $[b=0.45, S E=0.15, p=.002 ; M=7.56, S E=1.69$ vs. $M=7.20, S D=$ $1.93]$ and perceived sacrifice $[b=0.47, S E=0.17, p=.005 ; M=5.01, S D=2.26$ vs. $M=4.79, S D=$ 2.02]. These highly statistically robust effects demonstrate both that the manipulation of social benefit-which is very similar to that used in Studies 1-4-does indeed successfully manipulate perception of social benefit, as well as that in the absence of sacrifice information, social benefits are used to infer personal sacrifice.

Consequently, one would expect to see effects of condition on praise and character judgments. Indeed, there were effects of benefit on praise $[b=0.39, S E=0.14, p=.007 ; M=8.27, S D=1.67$ vs. $M=8.02, S D=1.81]$ and character $[b=0.27, S E=0.14, p=.057 ; M=7.71, S D=1.54$ vs. $M=$ $7.53, S D=1.81]$. It is interesting to note that despite these effects of benefit condition on praise and character judgments, these judgments were overall somewhat lower than in other studies, such as Studies 1 and 3, where sacrifice information was given. This suggests that the mere salience of sacrifice, even of modest magnitude, may lead to greater praise.

\section{Discussion}

Overall, these results accord with the theoretical framework. Although we observe a boundary condition here, in the sense that we now see effects of social benefit on praise and character, this 
boundary condition is fully consistent with the "character = sacrifice" heuristic. Whereas sacrifice information predominates when it is available, it is sometimes absent and must be inferred. Under such conditions, social benefit can itself be a heuristic for estimating sacrifice, allowing it to affect moral judgments such as praise and character.

These results also clear up a possible concern about Studies 1-4, which is that the null effect of social benefit could have been due to an unsuccessful manipulation of benefit, which may be difficult to evaluate without further context. Although evaluability could very well play a role in exacerbating these effects (see Study 6), a pure evaluability account would be distinct from the costly signaling explanation embedded in this article's theoretical framework. The current study directly demonstrates that such an account cannot be correct: Participants highly statistically robustly judged high-benefit donations to be more beneficial than low-benefit donations in a similar experimental design to Studies $1-4$, and this translated into effects of benefit on praise and character.

\section{Study 6: Task Transparency}

Study 6 tests the final potential boundary condition—task transparency (H7). People rely more on heuristics when the task is more opaque or complex, pushing the limits on systematic processing (e.g., Shah \& Oppenheimer, 2008). Thus, we would expect more transparent versions of the experimental task to be associated with greater reliance on benefit information, to the extent that people do indeed subscribe to some intuitive form of utilitarianism (Greene et al., 2008), believing that morality is tied to doing the greatest good for the greatest number.

Study 6 examines two ways of increasing task transparency. First, both Studies 6A and 6B relied on joint rather than separate evaluation (Hsee, 1996), with a high-sacrifice/low-benefit option directly contrasted with a low-sacrifice/high-benefit option. Joint evaluation tends to increase the evaluability of attributes by contextualizing them, making the task more transparent and increasing reliance on benefit information (H7a). Second, Studies 6A and 6B differ in the alignability of the benefits (Dhar \& Sherman, 1996; Gentner \& Markman, 1997), so that the two options' benefits were denominated in similar versus dissimilar categories. When the categories are more similar and therefore the benefits are more alignable, the increased task transparency should further increase the use of benefit information (H7b).

\section{Methods}

A total of 401 American participants (48\% female, $M_{\text {age }}=34.8$ ) were recruited for Study 6 . Participants were excluded if they answered more than one-fourth of a series of check questions incorrectly $(N=106)$. This more relaxed standard was used in our within-subjects studies (Studies 6 , 7, and S1) since the number of check questions was substantially greater in these studies due to the more complex design. However, the results are similar if participants making any errors are excluded.

Participants in Study 6A read about eight donations in four pairs (high-sacrifice/low-benefit versus low-sacrifice/high-benefit), based closely on the donations used in Study 1. The two donations were to similar causes and benefit was measured on the same scale. For example:

Rob donated \$125 to Disaster Relief Latin America. His donation was used to provide basic shelter to 1000 people for one month after a hurricane in Guatemala.

Chris donated $\$ 1250$ to Disaster Shelter Fund. His donation was used to provide basic shelter to 100 people for one month after a hurricane in Guatemala.

For each pair, participants judged "Which donation do you think was more morally praiseworthy?" as a forced-choice (e.g., "Rob's donation" or "Chris's donation"). The order of the two options and names of the donors and charities were counterbalanced, and order of the items was random. 
In Study 6B, the high-sacrifice/low-benefit and low-sacrifice/high-benefit donations within each pair were not easily alignable, because each pair pitted one cause against another. That is, the four causes used in Study 6A were staggered across different pairs, so that each cause appeared once in each version (high-sacrifice/low-sacrifice or the converse) but was paired against a donation to a different cause. For example:

Rob donated $\$ 125$ to Disaster Relief Latin America. His donation was used to provide basic shelter to 100 people for one month after a hurricane in Guatemala.

Chris donated $\$ 2000$ to Youth Blindness Cure. His donation was used to cure 1 child’s blindness in Ethiopia.

Studies 6A and 6B were otherwise identical.

\section{Results}

Unlike previous studies, participants systematically favored high-benefit over lower-benefit donations, even when the low-bneefit donations entailed greater sacrifice. This was especially true when the attributes were alignable $(\mathrm{H} 7 \mathrm{~b})$, but even held up when the attributes were not alignable in joint evaluation mode (H7a).

In Study 6A, participants strongly favored the low-sacrifice/high-benefit donor as more morally praiseworthy, selecting this choice for $82 \%$ of the pairs $[t(140)=11.98,95 \% \mathrm{CI}[3.07,3.50]$ out of 4 items, $p<.001$ in a one-sample test vs. $2, d=1.00]$. Thus, when highly alignable charitable causes are pitted against one another, people's evaluations of moral praise strongly track social benefit rather than personal sacrifice.

In Study 6B, when the causes were not readily alignable, participants still had a preference for the low-sacrifice/high- benefit donor, selecting this choice for $62 \%$ of the pairs $[t(153)=4.93,95 \%$ $\mathrm{CI}[2.30,2.69], p<.001, d=0.40]$. However, this preference was considerably weaker than in Study $\left.6 \mathrm{~A}, t(293)=5.39,95 \% \mathrm{CI}_{\text {diff }}[0.50,1.08], p<.001, d=0.63\right]$, suggesting that attribute alignability plays an important role in making these comparisons.

\section{Discussion}

In task transparency, we have another boundary condition on people's prioritization of personal sacrifice over social good-people favor actors maximizing social good when there is a clear comparison. Unfortunately, the separate evaluation cases examined in Studies 1-5 are probably more typical of the real world, where we usually hear about charitable acts individually. Nonetheless, this study highlights the practical significance of comparison shopping in the domain of prosocial behavior, suggesting that making comparisons easy can improve the reputational benefits of donating to more effective charities.

\section{Study 7: Social Signaling vs Warm Glow}

So far, we have looked only at third-party perceptions of personal sacrifice versus social benefit. This is important for understanding the signaling motives that donors face. Yet arguably, "looking good" is not the only motive for prosocial behaviour; we also aim to "feel good" or to accrue warm glow. Since there are plausible reasons either way as to whether warm glow would be more sensitive to social benefit compared to social signaling, Study 7 tested their relative sensitivity.

\section{Methods}

200 American participants (53\% female, $\left.M_{\text {age }}=38.5\right)$ were recruited for Study 7. Participants were excluded if they failed one or more attention checks embedded in self-report scales (e.g., "Please 
choose 2"; $N=4$ ) or answered more than one-fourth of a series of check questions incorrectly as in Study $6(N=27)$. However, the results are similar if participants making any errors are excluded (except as noted).

Participants completed scales for 4 different pairs of donations, blocked into 2 groups of items. Before completing the two items in the signaling block, participants were instructed: "For the next two pairs of donations, please imagine how your friends would react if they learned that you had made that donation." The next two screens presented pairs of donations contrasting a low-sacrifice/highbenefit and high-sacrifice/low-benefit option, which were modified versions of those used in Study 6A. For example:

Donation A. Giving $\$ 80$ to Disaster Relief Latin America, which can be used to provide basic shelter to 15 people for one month after a hurricane in Guatemala.

Donation B. Giving $\$ 400$ to Disaster Shelter Fund, which can be used to provide basic shelter to 3 people for one month after a hurricane in Guatemala.

Participants were prompted to "Imagine making each of these donations. Thinks of how your friends might react if they learned about it." They then completed the signaling measure ("Which donation do you think would impress your friends more with your generosity?") from -5 ("Donation A") to 5 ("Donation B") followed by a choice measure ("If you were presented with these two donation options, which one would you be more likely to choose?") on the same scale.

Before completing the two items in the warm-glow block, participants were instead instructed to "imagine what emotions you would experience from having made the donation." After reading the donation pair, participants were prompted to "Imagine making each of these donations. Think of how the knowledge of your donation would make you feel." They then completed the warm glow measure ("Which donation do you think would bring you more emotional gratification?") on the same scale as the signaling measure, followed by the same choice measure as in the signaling block.

The two blocks were presented in a counterbalanced order, the item order randomized within each block, and the four pairs of donations counterbalanced with condition. Within each item, the order of the two options and names of the charities were counterbalanced as in Study 6.

For exploratory purposes, three scales were administered after the main task. The 5-item impartial beneficence subscale of the Oxford Utilitarianism scale (Kahane et al., 2018) measures beliefs that everyone should be treated as moral equals (e.g., "If the only way to save another person's life during an emergency is to sacrifice one's own leg, then one is morally required to make this sacrifice"; ). The 7-item shortened empathy scale (Mehrabian \& Epstein, 1972) measures emotional empathy ("I am very upset when I see an animal in pain"). The 7-item "ability to modify self-presentation" subscale of the self-monitoring scale (Lennox \& Wolfe, 1984) measures attention to impression-formation concerns in social situations (e.g., "Once I know what the situation calls for, it's easy for me to regulate my actions accordingly"). All scale items were measured from -5 ("Strongly disagree") to 5 ("Strongly agree"). The order of the three scales was randomized, as was the order of the items within each scale.

\section{Results}

Participants believed that the more effective donations would yield more emotional gratification, but that the two donations had similar signaling value.

For the signaling items, the two donations were seen as yielding similar impressions from their friends $[t(168)=0.35, p=.72, d=0.03$ vs. $0 ; M=0.09, S D=3.46]$. In contrast, for the warm glow items, the low-sacrifice/high-benefit donation was seen as much more emotionally gratifying [ $t(168)$ 
$=21.11, p<.001, d=1.62$ vs. $0 ; M=3.58, S D=2.20]$. The difference between these two measures was also statistically significant $[t(168)=11.18, p<.001, d=1.20]$.

Participants also were much likelier to choose the low-sacrifice/high-benefit donation $[t(168)=$ $35.46, p<.001, d=2.73$ vs. $0 ; M=3.94, S D=1.44]$. This makes sense: Participants thought the two donations were equal in signaling value, whereas they thought the low-sacrifice/high-benefit donation was more emotionally gratifying-and, of course, it is more cost-effective. However, this preference differed in magnitude across the two conditions. When the choice prompt was preceded by questions about emotional gratification, their preference was stronger than when the choice prompt was preceded by questions about signaling $[t(168)=2.78, p=.006, d=0.24 ; M=4.15, S D=1.60$ vs. $M$ $=3.72, S D=1.90]$.

In our exploratory analyses of the individual difference scales, we found a significant positive correlation between utilitarianism and the belief that the more utilitarian (low-sacrifice/high-benefit) donation was a stronger social signal $[r(167)=.241, p=.002]$. (This effect was not significant in the subset of the sample that made no errors, possibly due to a lack of statistical power.) Notably, utilitarianism did not predict greater emotional gratification $[r(167)=.001, p=.99]$ or choices $[r(167)$ $=.058, p=.45]$. The empathy and self-monitoring scales did not predict any of these variables.

\section{Discussion}

Warm glow is much more sensitive to social benefit compared to social signaling. Moreover, contexts in which people are prompted to think about warm glow rather than social signaling lead them to favor donations higher in social benefit. This is good news because it suggests that nudges that put donors more into an emotional mindset as opposed to a signaling mindset, or those which encourage people to think of themselves rather than third-parties when they are giving, are likely to lead to giving that puts more weight on social benefit.

Nonetheless, this study has one important limitation, which is the use of a joint evaluation design, which we know leads people to attend more to social benefit information (Study 6). Since the purpose of this study was to compare the use of benefit information in their use for social signaling versus warm glow, this limitation does not undermine the conclusion that social benefit information is prioritized relatively more in warm glow. But this study does not permit claims about the absolute (as opposed to relative) magnitude of people's sensitivity to social benefit in emotional gratification.

The weak relationship between utilitarianism and warm-glow or choice is broadly consistent with other evidence that expressions of utilitarian moral philosophy have little predictive power over utilitarian choices or preferences (Johnson \& Ahn, 2022; Johnson \& Park, 2022). The finding that utilitarianism predicted only signaling beliefs, while provocative, should be taken with caution until replicated in a confirmatory context.

\section{General Discussion}

Prosocial actions entail, by definition, a cost to the actor and a benefit to society. But these costs and benefits are not always in strict proportion. Even a modest contribution to the most effective charities can do far more good than large contributions to ineffective charities (Caviola et al., 2020). Given this decoupling, this article asks: Why do people admire prosocial acts—is it driven by actor's personal sacrifice or the benefits to society?

Six studies demonstrate that personal sacrifice, but not social benefits, are associated with more positive reputational consequences of a prosocial action and with praise for that action (H1 and H2; Study 1). That is, people rely on a "character = sacrifice" heuristic for evaluating prosocial actions. Praiseworthiness appears to be largely a consequence of the action's reputational consequences, since independent evidence of the actor's reputation make sacrifice less diagnostic of praise (H3; Study 2). 
Overall, these results are consistent with costly signaling theory, which says that actions send strong signals of underlying traits, such as moral reputation, to the extent that they are costly (Gintis et al., 2001; Zahavi, 1975). Sacrifice, more than benefit, is a direct measure of cost-directly under the actor's control and more typically observable - and should therefore drive moral reputation as we find. These results are also consistent with character-based approaches to moral judgment, according to which praise and blame for individual actions flows from the consequences of those actions for the actor's reputation-their propensity to act cooperatively and trustworthily in the future (Uhlmann et al., 2015).

These studies also examined four possible boundary conditions, derived from prior research and theory. Two of these concern the type of prosocial action, asking the question "when is the "character = sacrifice' heuristic appropriate?" First, given that people are often parochial in their donations (Baron \& Szymanska, 2011; Nagel \& Waldmann, 2013), they might have a more favorable impression of highly beneficial donations directed toward their own country rather than toward foreigners. Put differently, people might care about donations to foreigners because it signals the donor's reputation, but they might care about domestic donations because they have empathically internalized the benefits to those recipients. However, there was only mixed evidence for this effect and, if it exists, it is likely small (H4; Study 3).

Second, people are known to differ in how think about time and money, including in charity contexts (Mogilner \& Aaker, 2009; Reed et al., 2007). Plausibly_and confirmed in Study S1 in the Supplementary Materials — sacrifice and benefits signal different things for time and money donations. For morality, sacrifice but not benefits always signal moral reputation for both time and money donations. But for competence, both sacrifice and benefits signal competence for money donations, whereas only benefits signal competence for time donations. Consequently, sacrifice has more generally positive signaling consequences for money than for time donations, and we correspondingly find that sacrifice is less diagnostic of character and less praiseworthy for time donations, holding benefits constant (H5; Study 4). There was also some evidence that benefits were associated with praise for time, but not for money, donations.

The other two potential boundary conditions concerned the informational environment, asking the question "when is the "character = sacrifice' heuristic needed?" The third potential boundary condition was the absence of sacrifice information. Under such conditions, social perceivers would want to infer sacrifice and could plausibly do so from the degree of social benefit, given that there is some-albeit imperfect - correlation between sacrifice and benefit (H6). This was confirmed in Study 5, which found clear evidence that benefits do drive praise when sacrifice is unknown.

Fourth, heuristics are especially important for navigating messy, complex, and ill-posed tasks, such as we often encounter in the real world. But sometimes tasks can be simplified by framing choices in joint evaluations (evaluating options side-by-side rather than separately) and by making the attributes as alignable as possible (referring to similar rather than dissimilar categories). When the task is streamlined in this way, heuristics such as the "character = sacrifice" heuristic are less needed for producing judgments, and people can rely more on their explicit theories of morality, which are likely to be at least somewhat utilitarian (Greene et al., 2008), favoring the greatest good for the greatest number (H7). Study 6 indeed found that restructuring the informational environment in these ways greatly increased the tendency to override sacrifice information with benefit information.

A final question is the relative weight that our emotions pay to social benefit, compared to the weight placed on benefit in social signaling. Study 7 found that social benefit information is far more important in contributing to "warm glow" than it is to social signaling; moreover, prompting people to think about warm glow rather than signaling led people to prefer making donations that were higher in social benefit. 


\section{Theoretical Implications}

This article contributes to several ongoing conversations in moral psychology, consumer behavior, and economics.

First, we contribute to moral psychology literature on altruism by distinguishing between the cost and benefit axes of altruistic actions. To our knowledge, only three articles to date have looked at this distinction (Burum et al., 2020; Kawamura et al., 2020; Zhang \& Epley, 2009); most of these studies do not look at moral reputation, and the sole exception (Burum et al., 2020) may have limited generalizability to real-world donation contexts as discussed in the introduction. More commonly, altruism is tested using tasks such as dictator games that conflate costs and benefits (e.g., Klein \& Epley, 2014). An important goal for future research will be to examine whether it is costs or benefits that drive many of the effects seen in these studies that conflate costs and benefits.

Second, we contribute to the economics literature, which has highlighted that donor reputation is an important motive for charitable giving (e.g., Glazer \& Konrad, 1996; Harbaugh, 1998), but has not articulated either how or why these effects occur. Prior economics literature leaves ambiguous whether costs or benefits are the key driver of these perceived reputational benefits, and for the most part this literature has not established that these benefits actually materialize. The current work, by focusing on social perceivers rather than actors, shows both that these reputational consequences are real and pinpoints why they occur.

Finally, the tests of boundary conditions contribute to several peripheral conversations, such as the role of parochialism in charitable giving, how people think about time and money, and how the informational environment constraints the use of heuristics. Perhaps the most novel theoretical innovation is the notion that evolutionary considerations, such as costly signaling, can supply the content of heuristics, while the informational environment can sharply influence their use. The "character = sacrifice" heuristic follows precisely from costly signaling theory, but the fact that we should have this heuristic in our heads does not settle the matter of when it should be used. The studies here find that people are quite adaptive in using this heuristic, showing a different pattern when the reputational meaning of the cue is different (e.g., high-sacrifice time donations tend to signal lower efficiency and therefore are not associated with competence) or when the informational environment makes it easy to avoid using it (e.g., in joint evaluation mode with highly alignable attributes).

\section{Practical Implications}

The opening paragraph of this article contemplated the apparent mismatch between the world's generosity and the social effectiveness of global charity. With this article's theorizing and empirics under our belts, we can conclude that this mismatch is likely due to a market failure. In large part, the market for charity is a market for reputation, and reputation does not follow the dictates of utilitarianism that seek the greatest good for the greatest number. Instead, sacrifice is often the goal in itself because of its positive reputational consequences. Any social good this happens to accomplish is, at best, icing on the cake. The situation may not be fully as dire as this-reputation-driven giving stands aside warmglow giving and, perhaps, pure altruism as motives for charity-but of course these other motives suffer their own diagnosed biases.

What advice might these results suggest for a particularly effective charity that wishes to maximize its charitable contributions? One questionable piece of advice would be to seek donations of time rather than money, since the reputational consequences of time donations appear more tied to benefit than to sacrifice (Studies 4 and S1). Moreover, other research finds that time donations are both more reputation-enhancing and produce a "warmer glow" than money donations (Johnson \& Park, 2020; Reed et al., 2007). Unfortunately, this suggestion suffers from a great obstacle-donations of time are probably far less efficient on average than donations of money (Singer, 1972), so even relatively effective donations of time will often be less effective than ineffective donations of money. 
However, these studies suggest several more promising alternatives. Study 3 found some evidence that people are sensitive to benefits when charities are domestic rather than foreign. Thus, highly effective charities can try to market particularly to domestic donors. (Conversely-reluctant though I am to offer this advice-relatively ineffective charities may wish to channel their efforts toward foreign donors to whom sacrifice rather than benefit is the ultimate objective.) However, since the evidence for this effect was relatively inconsistent, further work should examine this question more thoroughly before firm recommendations can be proffered.

A second possibility is for highly effective charities to denominate contributions primarily in terms of benefits, rather than costs. For example, rather than selecting an amount of money to donate, donors may choose how many beneficiaries they wish to help (with this number later converted into a monetary figure). Since benefit information drives reputation more when sacrifice is unknown (Study 5), de-emphasizing the monetary contribution may lead to larger donations. This would also be interesting to test explicitly in future work.

Third, highly effective charities can make the decision problem as transparent as possible. Study 6 found that people find highly effective charitable contributions to be more praiseworthy than ineffective ones, even if the more effective contribution was made at a lower cost, when this information is highly transparent. Thus, effective charities should make the impact of a donation easy to compare to ineffective competitors. Websites such as givewell.org are already leading the charge on this. Hopefully we will see more and more uptake of such comparisons to help people choose more effective charities.

Finally, since giving is done both for signaling motives and for emotional gratification motives, charities may have scope to nudge which of these motives plays a greater role in a donation decisions. Study 7 found that when donations are made with warm glow motives more in mind, people are more prone to choose effective charities compared to when donations are made with signaling motives in mind. The many efforts made by charities to get donors in touch with their emotions likely contribute to the harnessing of warm glow motives.

We may not like that so much charitable behavior is done for ulterior motives. But if our goal is to help the world, the best advice to charities and policy-makers may be to lean in to these motives and help donors to flaunt their donations as effectively as possible. 


\section{References}

Aknin, L. B., Van de Vondervoort, J. W., \& Hamlin, J. K. (2018). Positive feelings reward and promote prosocial behavior. Current Opinion in Psychology, 20, 55-59.

Andreoni, J. (1990). Impure altruism and donations to public goods: A theory of warm-glow giving. Economic Journal, 100, 464-477.

Ariely, D., Bracha, A., \& Meier, S. (2009). Doing good or doing well? Image motivation and monetary incentives in behaving prosocially. American Economic Review, 99, 544-555.

Barasch, A., Levine, E. E., Berman, J. Z., \& Small, D. A. (2014). Selfish or selfless? On the signal value of emotion in altruistic behavior. Journal of Personality and Social Psychology, 107, 393-413.

Barbey, A. K., \& Sloman, S. A. (2007). Base-rate respect: From ecological rationality to dual processes. Behavioral and Brain Sciences, 30, 241-297.

Baron, J., \& Szymanska, E. (2011). Heuristics and biases in charity. In D. M. Oppenheimer \& C. Y. Olivola (Eds.), The science of giving: Experimental approaches to the study of charity (pp. 215-235). New York, NY: Psychology Press.

Bates, D., Mächler, M., Bolker, B., \& Walker, S. (2014). Fitting linear mixed-effects models using lme4. Journal of Statistical Software, 67, 1-48.

Batson, C. D. (1987). Prosocial motivation: Is it ever truly altruistic? Advances in Social Psychology, 20, 65-122.

Batson, C. D., \& Shaw, L. L. (1991). Evidence for altruism: Toward a pluralism of prosocial motives. Psychological Inquiry, 2, 107-122.

Batson, C. D., Batson, J. G., Slingsby, J. K., Harrell, K. L., Peekna, H. M., \& Todd, R. M. (1991). Empathic joy and the empathy-altruism hypothesis. Journal of Personality and Social Psychology, 61, 413-426.

Bellezza, S., \& Berger, J. (2020). Trickle-round signals: When low status is mixed with high. Journal of Consumer Research, 47, 100-127.

Bellezza, S., Gino, F., \& Keinan, A. (2014). The red sneakers effect: Inferring status and competence from signals of nonconformity. Journal of Consumer Research, 41, 35-54.

Bentham, J. (1907). An introduction to the principles of morals and legislation. Oxford, UK: Clarendon Press. (Original work published 1789.)

Berger, J., \& Ward, M. (2010). Subtle signals of inconspicuous consumption. Journal of Consumer Research, 37, 555-569.

Berman, J. Z., Barasch, A., Levine, E. A., \& Small, D. A. (2018). Impediments to effective altruism: The role of subjective preferences in charitable giving. Psychological Science, 29, 834-844.

Berman, J. Z., Levine, E. E., Barasch, A., \& Small, D. A. (2015). The braggart's dilemma: On the social rewards and penalties of advertising prosocial behavior. Journal of Marketing Research, 52, 90-104.

Bhogal, M. S., Farrelly, D., Galbraith, N., Manktelow, K., \& Bradley, H. (2020). The role of altruistic costs in human mate choice. Personality and Individual Differences, 160, 109939.

Burum, B., Nowak, M. A., \& Hoffman, M. (2020). An evolutionary explanation for ineffective altruism. Nature Human Behaviour, 4, 1245-1257.

Carlson, R. W., \& Zaki, J. (2019). Belief in altruistic motives predicts prosocial actions and inferences. Psychological Reports, 125, 2191-2212.

Carlson, R. W., \& Zaki, J. (2019). Good deeds gone bad: Lay theories of altruism and selfishness. Journal of Experimental Social Psychology, 75, 36-40.

Caviola, L., Schubert, S., Teperman, E., Moss, D., Greenberg, S., \& Faber, N. S. (2020). Donors vastly underestimate differences in charities' effectiveness. Judgment and Decision-Making, 15, 509-516.

Cheng, Y., Mukhopadhyay, A., \& Williams, P. (2020). Smiling signals intrinsic motivation. Journal of Consumer Research, 46, 915-935. 
Cushman, F. (2008). Crime and punishment: Distinguishing the roles of causal and intentional analyses in moral judgment. Cognition, 108, 353-380.

De Freitas, J., \& Johnson, S. G. B. (2018). Optimality bias in moral judgment. Journal of Experimental Social Psychology, 79, 149-163.

Dhar, R., \& Sherman, S. J. (1996). The effect of common and unique features in consumer choice. Journal of Consumer Research, 23, 193-203.

Fan, S., Headney, D., Laborde, D., Mason-D’Croz, D., Rue, C., Sulser, T. B., \& Wiebe, K. (2018). Quantifying the cost and benefits of ending world hunger and undernutrition: Examining the differences among alternative approaches. IFPRI Issue Brief. Washington, DC: International Food Policy Research Institute.

Frank, R. H. (1988). Passions within reason: The strategic role of the emotions. New York, NY: Norton.

Gates Foundation (2020). From inspiration to action: What will it take to end malaria? http:/ / endmalaria2040.org.

Gentner, D., \& Markman, A. B. (1997). Structure mapping in analogy and similarity. American Psychologist, 52, 45-56.

Gershon, R., \& Cryder, C. (2018). Goods donations increase charitable credit for low-warmth donors. Journal of Consumer Research, 45, 451-469.

Gintis, H., Smith, E., \& Bowles, S. (2001). Costly signaling and cooperation. Journal of Theoretical Biology, 213, 103-119.

Giving USA (2022). Giving USA 2022: The annual report on philanthropy for the year 2021. Chicago, IL: Giving USA.

Glazer, A., \& Konrad, K. A. (1996). A signaling explanation for charity. American Economic Review, 86, 1019-1028.

Gneezy, U., Keenan, E. A., \& Gneezy, A. (2014). Avoiding overhead aversion in charity. Science, 346, 632-635.

Goodwin, G. P., Piazza, J., \& Rozin, P. (2014). Moral character predominates in person perception and evaluation. Journal of Personality and Social Psychology, 106, 148-168.

Greene, J. D., Morelli, S. A., Lowenberg, K., Nystrom, L. E., \& Cohen, J. D. (2008). Cognitive load selectively interferes with utilitarian moral judgment. Cognition, 107, 1144-1154.

Griskevicius, V., Tybur, J. M., Sundie, J. M., Cialdini, R. B., Miller, G. F., \& Kenrick, D. T. (2007). Blatant benevolence and conspicuous consumption: When romantic motives elicit strategic costly signals. Journal of Personality and Social Psychology, 93, 85-102.

Griskevicius, V., Tybur, J. M., \& van den Bergh, B. (2010). Going green to be seen: Status, reputation, and conspicuous conservation. Journal of Personality and Social Psychology, 98, 392-404.

Hamilton, W. D. (1964). The genetical evolution of social behaviour. Journal of Theoretical Biology, 7, 116.

Harbaugh, W. T. (1998). The prestige motive for making charitable transfers. American Economic Review, $88,277-282$.

Hardy, C. L., \& van Vugt, M. (2006). Nice guys finish first: The competitive altruism hypothesis. Personality and Social Psychology Bulletin, 32, 1402-1413.

Hsee, C. K. (1996). The evaluability hypothesis: An explanation for preference reversals between joint and separate evaluations of alternatives. Organizational Behavior and Human Decision Processes, 67, 247257.

Hsee, C. K., \& Rottenstreich, Y. (2004). Music, pandas, and muggers: On the affective psychology of value. Journal of Experimental Psychology: General, 133, 23-30.

Inbar, Y., Pizarro, D. A., \& Cushman, F. (2012). Benefiting from misfortune: When harmless actions are judged to be morally blameworthy. Personality and Social Psychology Bulletin, 38, 52-62. 
Johnson, S. G. B. (2019). Moral reputation and the psychology of giving: Praise judgments track personal sacrifice rather than social good. In A. K. Goel, C. M. Seifert, \& C. Freksa (Eds.), Proceedings of the 41. Annual Conference of the Cognitive Science Society (pp. 499-505). Austin, TX: Cognitive Science Society.

Johnson, S. G. B., \& Park, S. Y. (2021). Moral signaling through donations of money and time. Organizational Behavior \& Human Decision Processes, 165, 183-196.

Johnson, S. G. B., Merchant, T., \& Keil, F.C. (2020). Belief digitization: Do we treat uncertainty as probabilities or as bits? Journal of Experimental Psychology: General, 149, 1417-1434.

Johnson, S. G. B., \& Rips, L. J. (2015). Do the right thing: The assumption of optimality in lay decision theory and causal judgment. Cognitive Psychology, 77, 42-76.

Jordan, J. J., Sommers, R., Bloom, P., \& Rand, D. G. (2017). Why do we hate hypocrites? Evidence for a theory of false signaling. Psychological Science, 28, 356-368.

Kahane, G., Everett, J. A. C., Earp, B. D., Caviola, L., Faber, N. S., Crockett, M. J., \& Savulescu, J. (2018). Beyond sacrificial harm: A two-dimensional model of utilitarian psychology. Psychological Review, 125, 131-164.

Kawamura, Y., Ohtsubo, Y., \& Kusumi, T. (2020). Effects of cost and benefit of prosocial behavior on reputation. Social Psychological and Personality Science, 12, 452-460.

Klein, N., \& Epley, N. (2014). The topography of generosity: Asymmetric evaluations of prosocial actions. Journal of Experimental Psychology: General, 143, 2366-2379.

Lennox, R. D., \& Wolfe, R. N. (1984). Revision of the Self-Monitoring Scale. Journal of Personality and Social Psychology, 46, 1349-1364.

Lin-Healy, F., \& Small, D. A. (2012). Cheapened altruism: Discounting personally affected prosocial actors. Organizational Behavior and Human Decision Processes, 117, 269-274.

Liu, W., \& Aaker, J. (2008). The happiness of giving: The time-ask effect. Journal of Consumer Research, $35,543-557$.

MacAskill, W. (2015). Doing good better: How effective altruism can help you make a difference. New York, NY: Penguin.

MacFarquhar, L. (2016). Strangers drowning: Impossible idealism, drastic choices, and the urge to help. New York, NY: Penguin.

McKinsey (2020). Pathways to a low-carbon economy: Version 2 of the global greenhouse gas abatement cost curve. New York, NY: McKinsey.

McShane, B. B., \& Böckenholt, U. (2017). Single-paper meta-analysis: Benefits for study summary, theory testing, and replicability. Journal of Consumer Research, 43, 1048-1063.

Mehrabian, A., \& Epstein, N. (1972). A measure of emotional empathy. Journal of Personality, 40, 525543.

Mill, J. S. (1998). Utilitarianism. Oxford, UK: Oxford University Press. (Original work published 1861.)

Miller, G. (2009). Spent: Sex, evolution, and consumer behavior. New York, NY: Penguin.

Mogilner, C., \& Aaker, J. (2009). “The time vs. money effect”: Shifting product attitudes and decisions through personal connection. Journal of Consumer Research, 36, 277-291.

Nagel, J. and Waldmann, M. (2013). Deconfounding distance effects in judgments of moral obligation. Journal of Experimental Psychology: Learning, Memory, and Cognition, 39, 237-252.

Newman, G. E., \& Cain, D. M. (2014). Tainted altruism: When doing some good is evaluated as worse than doing no good at all. Psychological Science, 25, 648-655.

Nowak, M. A., \& Sigmund, K. (2005). Evolution of indirect reciprocity. Nature, 437, 1291-1298.

Null, C. (2011), Warm glow, information, and inefficient charitable giving. Journal of Public Economics, 95, 455-465.

Okada, E. M. and Hoch, S. J. (2004). Spending time versus spending money. Journal of Consumer Research, 31, 313-323. 
Olivola, C. Y., \& Shafir, E. (2013). The martyrdom effect: When pain and effort increase prosocial contributions. Journal of Behavioral Decision Making, 26, 91-105.

Park, B., \& Rothbart, M. (1982). Perception of out-group homogeneity and levels of social categorization: Memory for the subordinate attributes of in-group and out-group members. Journal of Personality and Social Psychology, 42, 1051-1068.

Price, M. E. (2003). Pro-community altruism and social status in a Shuar village. Human Nature, 14, 191-208.

Rand, D. G., \& Nowak, M. A. (2013). Human cooperation. Trends in Cognitive Sciences, 17, 413-425.

Reed, A., Aquino, K., \& Levy, E. (2007). Moral identity and judgments of charitable behaviors. Journal of Marketing, 71, 178-193.

Saini, R., \& Monga, A. (2008). How I decide depends on what I spend: Use of heuristics is greater for time than for money. Journal of Consumer Research, 34, 914-922.

Savary, J., \& Goldsmith, K. (2020). Unobserved altruism: How self-signaling motivations and social benefits shape willingness to donate. Journal of Experimental Psychology: Applied, 26, 538-550.

Shah, A. K., \& Oppenheimer, D. M. (2008). Heuristics made easy: An effort-reduction framework. Psychological Bulletin, 134, 207-222.

Singer, P. (2015), The most good you can do: How effective altruism is changing ideas about living ethically. New Haven, CT: Yale University Press.

Singer, P. (1972). Famine, affluence, and morality. Philosophy and Public Affairs, 1, 229-243.

Slovic, P. (2007). "If I look at the mass I will never act": Psychic numbing and genocide. Judgment and Decision Making, 2, 79-95.

Small, D. A., Loewenstein, G., \& Slovic, P. (2007). Sympathy and callousness: The impact of deliberative thought on donations to identifiable and statistical victims. Organizational Behavior and Human Decision Processes, 102, 143-153.

Smith, A. (1984) The theory of moral sentiments. Indianapolis, IN: Liberty Fund. (Original work published 1759.)

Smith, E. A., \& Bliege Bird, R. L. (2000). Turtle hunting and tombstone opening: Public generosity as costly signaling. Evolution and Human Behavior, 21, 245-261.

Spence, M. (1973). Job market signaling. Quarterly Journal of Economics, 87, 355-374.

Sperber, D., \& Baumard, N. (2012). Moral reputation: An evolutionary and cognitive perspective. Mind \& Language, 27, 495-518.

Sundie, J. M., Kenrick, D. T., Griskevicius, V., Tybur, J. M. Vohs, K. D., \& Beal, D. J. (2011). Peacocks, Porsches, and Thorstein Veblen: Conspicuous consumption as a sexual signaling system. Journal of Personality and Social Psychology, 100, 664-680.

Tingley, D., Yamamoto, T., Hirose, K., Keele, L., \& Imai, K. (2014). Mediation: R package for causal mediation analysis. Journal of Statistical Software, 59.

Trivers, R. L. (1971), The evolution of reciprocal altruism. Quarterly Review of Biology, 46, 35-57.

Tversky, A., \& Kahneman, D. (1983). Extensional versus intuitive reasoning: The conjunction fallacy in probability judgment. Psychological Review, 90, 293-315.

Uhlmann, E. L., Pizarro, D. A., \& Diermeier, D. (2015). A person-centered approach to moral judgment. Perspectives on Psychological Science, 10, 72-81.

Veblen, T. (1899/1994). The theory of the leisure class. London, UK: Penguin.

Walasek, L., \& Brown, G. D. A. (2021). Incomparability and incommensurability in choice: No common currency of value? Available at PsyArXiv: https://psyarxiv.com/suw47/

Warren, C., \& Mohr, G. S. (2019). Ironic consumption. Journal of Consumer Research, 46, 246-266.

Willer, R. (2009). Groups reward individual sacrifice: The status solution to the collective action problem. American Sociological Review, 74, 23-43. 
Wright, R. (1994), The moral animal: Why we are the way we are: The new science of evolutionary psychology. New York, NY: Vintage.

Zahavi, A. (1975). Mate selection-A selection for a handicap. Journal of Theoretical Biology, 53, 205214.

Zhang, Y., \& Epley, N. (2009). Self-centered social exchange: Differential use of costs versus benefits in prosocial reciprocity. Journal of Personality and Social Psychology, 97, 796-810. 


\title{
Supplementary Materials for
}

\author{
Dimensions of Altruism: \\ Do Evaluations of Prosocial Behavior Track Social Good or Personal Sacrifice?
}

\section{Study S1: Morality versus Competence Signaling}

Study S1 examines auxiliary assumptions needed to flesh out our model. Specifically, I predicted that whereas inferences about morality would be similar for time and money donations, inferences about competence would differ. I anticipated that sacrifice would be associated with competence for money, but not time, donations. Conversely, I predicted that benefits would be associated with competence at least as much for time as for money donations.

\section{Methods}

100 American participants (40\% female, $\left.M_{\text {age }}=38.6\right)$ were recruited for Study S1. Due to the within-subjects design, a larger number of check questions was included, and participants were excluded if they answered more than one-fourth of these questions incorrectly $(N=31)$.

Participants read about 4 donations of money and 4 donations of time, using the stimuli from Studies 1 and 4. As in the main studies, this either involved a smaller (e.g., \$200 or 3 hours) or larger sacrifice (e.g., $\$ 2000$ or 3 days), and the donation was either low (e.g., curing 1 child's blindness; helping 2 flood victims) or high in benefit (e.g., curing 10 children's blindness; helping 20 flood victims). Latin squares counterbalanced the assignment of sacrifice and benefit conditions to the 4 money and 4 time vignettes. Thus, each participant responded to each of the 4 money vignettes, one in each condition, and likewise responded to each of the 4 time vignettes, one in each condition. The 8 items were presented in a random order.

Rather than rating character and praise as in the main studies, participants evaluated the protagonist of each vignette on 6 dimensions. Three dimensions were related to morality ("kind," "caring," "empathetic"; $\alpha=.97$ ) and three to competence ("efficient", "organized", "competent"; $\alpha$ $=.96)$. These ratings were made in a separate random order for each item.

\section{Results}

To determine the signaling power of sacrifice and benefit, we calculated difference scores, presented in Table S1. For example, to calculate the morality signaling power of sacrifice for money donations, we averaged the morality judgments for the two high-sacrifice conditions (highsacrifice/low- benefit and high-sacrifice/high-benefit) and subtracted from this the morality judgments for the two low-sacrifice conditions (low-sacrifice/low-benefit and low-sacrifice/highbenefit). Thus, if higher levels of sacrifice signal higher levels of morality than lower levels of sacrifice, these scores should be positive and vice versa.

For morality, the inference patterns were the same for money and time donations. Sacrifice signaled morality for both money and time donations, as shown in the top row of Table S1 ( $p$ s $<.05$, $d=0.35$ and 0.31 , respectively), and these magnitudes did not differ between time and money donations $[t(68)=0.39, p=.70, d=0.05]$. Conversely, benefit did not signal morality either for money or time donations ( $p$ s $>.14, d=0.18$ and 0.11 ), with time and money donations again not differing $[t(68)=0.14, p=.89, d=0.02]$. 
For competence, however, the patterns differed between time and money donations. Sacrifice signaled competence for money donations $(p<.001, d=0.54)$ but not time donations $(p=.42, d=$ $0.10)$, with the difference between money and time donations reaching significance $[t(68)=2.11, p=$ $.039, d=0.25$ ]. Conversely, benefit signaled competence both for money and time donations $(p s<$ $.01, d=0.30$ and 0.33$)$, with money and time donations not significantly differing $[t(68)=0.80, p=$ $.43, d=0.10]$.

\begin{tabular}{|c|c|c|}
\hline & \multicolumn{2}{|c|}{ Morality } \\
\hline & Money & Time \\
\hline Sacrifice & $0.26(0.09) * *$ & $0.22(0.09) *$ \\
\hline \multirow[t]{3}{*}{ Benefit } & $0.12(0.08)$ & $0.10(0.11)$ \\
\hline & \multicolumn{2}{|c|}{ Competence } \\
\hline & Money & Time \\
\hline Sacrifice & $0.38(0.08) * * *$ & $0.09(0.12)$ \\
\hline Benefit & $0.25(0.10) * *$ & $0.38(0.14)$ ** \\
\hline
\end{tabular}

Table S1. Difference scores (SEs) in morality and competence signaling in Study S1.

\section{Discussion}

Overall, these results indicate that the key difference between money and time donations is that, holding constant benefit, degree of sacrifice signals competence only for money donations (presumably because large donations imply high income), whereas people do not think that large time sacrifices correspond to higher competence (presumably because this implies that the donor was inefficient or shirking). Conversely, sacrifice signals morality equally for both money and time donations. On balance, these results together imply that the overall signaling power of sacrifice is greater for money than for time donations.

\section{Internal Meta-Analysis of Studies 1-4}

Studies 1-4 and their replications consist of 8 experiments with over 2000 participants, all relying on very similar designs. Here, an internal meta-analysis of all 8 studies is conducted to achieve maximum statistical power and to quantify the strength of the evidence for the three moderating variables tested in Studies 2-4 (character information, domestic beneficiaries, time donations), as recommended by McShane and Böckenholt (2017).

Separate multilevel models on character and praise judgments were fit on the pooled data. As fixed factors, these models included predictors for the manipulations - sacrifice and benefit, coded as for the analyses of the Studies 1-4 data (sacrifice: $-1=$ low, $0=$ medium, $1=$ high; benefit: $-1 / 2=$ low, $+1 / 2=$ high $)$; for the moderators_-character information $(0=$ Studies $1,3,4 ; 1=$ Study 2$)$, domestic victims $(0=$ Studies $1,2,4 ; 1=$ Study 3$)$, and time donation $(0=$ Studies $1,2,3 ; 1=$ Study 4$)$; and 6 interaction terms for each combination of manipulation and moderator. Random intercepts were included for vignette and study.

The results are shown in Table S2. In the absence of moderating effects, character and praise judgments are both predicted by the degree of sacrifice (H1) but not benefit $(\mathrm{H} 2)$. None of the 
moderators had a main effect on either character or praise, indicating that character and praise judgments were overall similar regardless of the presence of character information, the country benefited, or whether the donations are of money or time. However, two moderating effects were significant and consistent with the results of the individual studies. Sacrifice had a significantly smaller impact on character judgments when character information was available ( $\mathrm{H} 3 \mathrm{a})$ and when the donations were of time rather than money (H5), but not when the donations were domestic rather than foreign (H4). Although these did not manifest in significant moderating effects on praise judgments, the moderated mediation models reported in Studies 2 and 4 found that the indirect effects of sacrifice (but not benefit) differed depending on whether character information was provided (H3b) and whether the donation was of time or money $(\mathrm{H} 5 \mathrm{~b})$.

Overall, the results of the internal meta-analysis confirm those reported in individual studies.

\begin{tabular}{|c|c|c|c|}
\hline & & \multicolumn{2}{|c|}{ Dependent Variable } \\
\hline & & Character & Praise \\
\hline \multirow[t]{2}{*}{ Manipulations } & Sacrifice & $0.45(0.11) * * *$ & $0.39(0.11)^{* *}$ \\
\hline & Benefit & $0.04(0.15)$ & $0.17(0.13)$ \\
\hline \multirow[t]{3}{*}{ Moderators } & Character & $0.31(0.33)$ & $0.08(0.31)$ \\
\hline & Domestic & $0.14(0.32)$ & $-0.08(0.30)$ \\
\hline & Time & $0.08(0.32)$ & $-0.20(0.30)$ \\
\hline \multirow[t]{6}{*}{ Interactions } & Sacrifice $x$ Character & $-0.39(0.15) *$ & $-0.16(0.15)$ \\
\hline & Sacrifice $x$ Domestic & $-0.09(0.15)$ & $-0.03(0.15)$ \\
\hline & Sacrifice $x$ Time & $-0.34(0.15) *$ & $-0.28(0.15)^{\circ}$ \\
\hline & Benefit x Character & $0.17(0.21)$ & $0.12(0.19)$ \\
\hline & Benefit x Domestic & $-0.06(0.20)$ & $0.06(0.19)$ \\
\hline & Benefit $x$ Time & $0.16(0.20)$ & $0.17(0.19)$ \\
\hline
\end{tabular}

Table S2. Meta-analytic multilevel model predicting character and praise judgments from sacrifice and benefit and the moderators tested in Studies 2-4. 